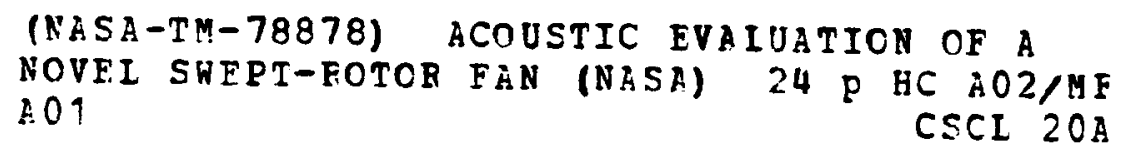

\title{
ACOUSTIC EVALUATION OF A NOVEL SWEPT-ROTOR FAN
}

by James G. Lucas, Richard P. Woodward, and Michael J. MacKinnon Lewis Research Center

Cleveland, Ohio 44135

TECHNICAL PAPER to be presented at the Eleventh Fluid and Plasma Dynamics Conference sponsored by the American Institute of Aeronautics and Astronautics Seattle, Washington, July 10-12, 1978 
by James G. Lucas, Richard P. Woodward, OF POOR QUALITY and Michael J. Mackinnon

National Aeronautics and Space Administration Lewis Research Center Cleveland, Ohio 44135

\section{Abstract}

Inlet noise and aerodynamic perfomance are presented for a high tip speed fan designed with rotor blade leading edge sweep that gives a subsonic component of inlet Mach number normal to the edge at all radii. The intent of the design was to minimize the generation of rotor leading edge shock waves thereby minimizing multiple pure tone noise. sound power level and spectral comparisons are made with several high-speed fans of conventional design. Results showed multiple pure tone noise at levels below those of some of the other fans and this noise was initiated at a higher tip speed. Aerodynamic performance of the fan did not meet design goals for this first build which applied conventional design procedures to the swept fan geometry.

\section{Introduction}

For the past decade or more a very considerable effort has been made to lower the noisc generated by turbofan engines. Early studies showed that the dominating jet noise could be greatly reduced by an increase in the fan bypass ratio, and this has become a standard feature of all subsequent designs. With the primary jet noise reduced successfully, the fan turbomachinery noise was exposed in the overall noise spectrum as the predominant noise source, and much attention was focused on both fan source noise reduction and noise absorbing concepts to quiet the fan noise. Efforts to reduce source noise showed that low fan tip speed was very desirable for several reasons and as a result the effort in noisereduction work on high speed fans at NASA-Lewis Research Center lagged for a period.

The high-speed fan has an acoustic disadvantage relative to its low-speed counterpart in producing an additional component of noise, the multiple pure tones that arise from the spatially nonuniform pattern of shock waves associatcd with the supersonic inlet flow relative to the rotor blading. However, from the standpoint of the engine as a system, the high-speed fan has a significant advantage in permitting either the turbine to be of smaller diameter and fewer stages, or a fan-drive gear box to be eliminated. The resulting lower potential cost, weight, and complexity of the highspeed fan are advartages that motivated a resurgence of Interest in attempts to reduce its noise.

In response to a NASA-Lewis request for proposals aimed primarily toward source noise reduction concepts for high speed fans, the Bolt, Beranek and Newman Company, with AVCO-Lycoming as a subcontractor, proposed and was contracted to design and fabricate a fan incorporating a novel concept which had potential for significantly reducing the amount of shock related noise. Their concept, which was outlined in Ref. 1 and detailed in Ref. 2 suggests that if the fan rotor blade leading edge can be considered analogous to a supersonic airplane wing leading edge, then sweeping the rotor edge properly should greatiy reduce the production of shock waves.

The principle involved in the airplane's sweptleading-edge wing states that the flow effects on both the edge and the airfoil section behind the edge depend only upon the component of the relative incoming Mach number which is normal to the edge; the component parallel to the edge can produce no shock or flow effects because it never crosses the edge. This theory was first alluded to in 1935 by Buseman and was properly defined a decade later by Jones. (3) Bliss (4) patented the concept of applying the swept-edge to a supersonic rotor blade for the purpose of shock control and shock-related noise reduction. It is this patent which forms the basis of the $B B N$ proposal for the fan described herein.

An additional noise reduction concept, sweeping of the stator leading edge, was incorporated in this $f$ an design and was intended to reduce the production of rotor-stator interaction noise at blade passage frequency. This concept is not new but for the present design much effort was expended on a detailed radial analysis of the rotor wake strength, width, position, swirl, axial velocity, and streamline changes in moving from the rotor to the stetor. This information was used in selecting a radiallyvarying sweep on the stator leading edge to maintain the trace speed of the wake along the edge subsonic. However, because a static acoustjc test facility has more inlet turbulence and circumferential inlet flow distortion than the fan experierces in flight, with resultant production of spurious tone noise, the beneficial effect of the swept stator on tone noise is likely to be difficult to measure without the aid of cartfully controlled rotor inflow and a reference unswept scator. A]so, at supersonic tip speed the rotor-alone field is a strong potential source of tone noise that could mask rotor-stator interaction tone noise. For these reasons, the subject of the present report is confined to the acoustic effects of the swept rotor on inlet noise production.

The fan resulting from the cooperative design effort among the contractor, subcontractor and NASA-Lewis was constructed with a nominal tip diameter of $500 \mathrm{~mm}(20 \mathrm{in}$.). It was sized and configured for testing in both the acoustic and aerodynamic test facilities at NASA-Lewis. The present report documents the results of testing in the acoustic test facility. During testing the fan was operated over the speed range from 50 to 100 percent of design corrected speed, and over all or part of five different operating lines. Tests were made with both a bellmouth inlet and an inlet with simulated flight-type internal contours and a thicker lip for static testing. Additional tests were made using a turbulence-reducing honeycomb/ screen flow control device over the flight. inlet in an attempt to reduce the excess blade-passage tone noise associated with inflow disturbances interacting with the rotor. 
The fan (termed QF-12) designed to incorporate the swept rotor uses conventional serodynemic ranges and 1 imits on such paremeters so solidtty, losses, tadial work distribution and diffusion factor. Design parameters selected were tip speed of $480 \mathrm{~m} / \mathrm{sec}$ preseure ratio of 1.60 , and an inlet apeciflc annular flow of $199 \mathrm{~kg} / \mathrm{sec}-\mathrm{m}^{2}$.

It 1. destred to have the component of the incoming relative Mach number normal to the rotor leading edge as much below 1.0 as possible, preferably low enough that the rise within the interblade channel would not increase it above 1.0. With a decrease in normal Mach number the leading edge sweep angle becomes steeper and the blade - tresses Increase, so eventually some form of compromise is needed. Early aeromechanteal design Iterations on this fan demonstrated conclusively thet absonic normal Mach number could not be achleved with a single forward or rearward oweep. It was necessary to employ a reversal of the sweep angle at about mid-span to achieve blade with mechanical integrity. This was accomplished in part by utilizing the compressive stresses due to the bending moments resulting from nonradial stackIng of the section centers of gravity to counteract - portion of the centrifugal tensile stresses. With this cheme, combined with iterating and carefully locating the radiel position of the sweep reveran, a deaign was achieved which had a satisfactory stesdy-state stress pattern, appropriate section chords and thus solidities, and radiallyvarying sweep angle which yielded normal Mach number varying from 0.83 at the hub to 0.91 from mid-span to the tip. This Mach number range was expected to satisfy the subsonic edge criterion for the coustic concept, though it would probably permit some channel Mach numbers to be alightly superconic. Because of the subsonic normal Mach number at the rotor edge, the designers chose to use double circular arc alrfoll sections on the rotor rother than the multiple circular arc or special alrfolls normally used on fans of this high tip speed range.

The designers realized that complete eliminatIon of shocks in the inlet was impossible even with the "ubbsonic" edge because weak shock systems would originate at the intersection of the blade t1p with the casing wall, at the sweep reversal point which is a discontinuity of the edge, and fron leading-edge thickness effects. These weak chock aystems were expected to have only a mall effect on multiple-pure-tone noise when welghed againat the beneficial effect on noise of the reduction of the major source of such shock systems, the strong leading edge shocks of conventional h1gh-speed fans.

Vibration and flutter analyois of the resultIng rotor blade indicated problem in this area, and art-apan shroud was added to ralse the blade natural frequencles and dampen vibrations. The damper was located far enough back in the Interblade channel that any shock waves from its leading edge should be contained within the channel and thus not produce forward-rediated nolse.

$A$ crose-section of the final fan des 1 gn is shown on F18. 1 and a photograph is shown on F18. 2 . Hore detalled information on the swept rotor design and on the awept atator can be found in Refs. 1 and 2.

\section{Test Rec1lity}

The fan hown in P1gs, I and 2 was installed for coustc teeting in the NASA-Lewis Engine Fan and Jet Nolse facllity which has been described in detall in Ref. 5. Figure 3 shows the fan with it.s modffied flight-type inlet installed in the factlity and also shows some of the fixed microphones used for far-field nolse measurements. Plan and elevation vlews of the facility are shown in Fig. 4 . callbration of the chamber Indicated that it can be considered anechoic within $1 \mathrm{~dB}$ at frequencies bove $500 \mathrm{~Hz}$. The chamber ruy be operated with inlet flow elther through the ellancer shown on Fig. 4 or through asplrsting $f l \cdots$, ceiling and walls. All noise data presented $t:$ ' $\cdots$ in were obtained with inlet air flowing through it ilencer. The fan is driven by a varfable-speed ef. : :ic motor and speedincreasing gearbox locuted in an acoustically isolated room. The fan discharges into a collector in the motor-drive room from which the alr exhausts through two mufflers and flow-control valves to the atmoephere outside the building. The test facility has an array of fixed far-field microphones on a 7.6 meter $(25 \mathrm{ft})$ radius centered at the fan-inlet face. These are positioned at $10^{\circ}$ spacings from $0^{\circ}$ to $90^{\circ}$ from the fan inlet axio.

\section{Fan Hardware}

The fan assembly, other than blading, was of heavy construction for rigidity and durability. A soft rub trip was provided in the casing over the rotor tipa to prevent blade damage in the event of a rub.

Three different inlet assemblies were used with this fan for the tests reported herein. Most of the data were obtalned with an inlet having flight-type internal contours, which was in fact the identical unit used on the tests reported in Ref. 5. Some tests are also reported using this same inlet with the addition of the turbulence-reducing honeycomb/ screen Inlet flow control device reported in Ref. 6 , and 11 lustrated in Figs. 5 and 6 . In addition, the fan was also tested with the bellmouth inlet 1llustrated in $\mathrm{F} 1 \mathrm{~g} .7$.

Although the testing of this fan was primarily for acoustic evaluation, sufficient serodynamic Instrunentation was provided to establish the over11 operating point and to permit an assessment of the fan' overall aerodynamic performance. The in- trumentation included thermocouples and static pressure taps in the inlet asembly for inlet mass flow calculations, and four 5-point radial rakes at the fan diecharge measuring total temperature and pressure. These measurements were processed through - pressure ultiplexer and computer system to calculate the aerodynamic performance parameters. All performance parameters were corrected to standard day condition $\left(288.2^{\circ} \mathrm{K}, 10.13 \mathrm{~N} / \mathrm{cm}^{2}\right)$.

\section{Test Procedure}

A rotor blade having the design complexity of the present one had never before been tested, and because of this it was necessary to carefully assess the aerodynamic and mechanical performance at each operating condition before any phase of URIGINAT, PAGE 
condition. Operation began with low speeds and low aerodynamic loading, then progressed slowly to higher speed and loading. Testing with most combinations of operating line and inlet hardware covered the speed range from 50 to 100 percent of design in increments of 5 or 10 percent.

S1x samples of all aerodynamic measurements were obtained at each operating point by an automatic digital data encoder. These six samples were averaged and from them the aerodynamic performance was computer-processed on line. A continuous trace of fan discharge pressure against inlet static pressure was displayed on an $X-Y$ recorder for comparison with a predicted standard operating line plotted on the recorder chart.

Strain gages were placed on six of the rotor blades in locations appropriate for measuring the maximum predicted steady-state stress and the vibratory stresses for several predicted low-order modes. The steady-state and vibratory stresses were separately displayed on oscilioscopes and were continuously monicored visually.

Acoustic data were obtained concurrently with the aerodynamic data. Signals from all the microphones were processed on-line by a one-third-octave analyzer with the output recorded digitally on magnetic tape. The three data samples on tape were averaged and processed off-line by computer using the analysis programs detailed in Ref. 7 . Simultaneously with the on-line analysis, the microphone outputs were also recorded as analog signals on magnetic tape for off-line analyses as desired.

\section{Results and Discussion}

\section{Aerodynamic Performance}

An analysis and assessment of the fan acoustic characteristics requires some knowledge of the aerodynamic characteristics. It must be determined if the fan is performing aerodynamically as designed, and if not, how any differences would be expected to affect the noise generation processes and relate to the measured noise output. This is particularly true for a fan such as QF-12 whose source noise reduction concept is intimately related to the aerodynamic design details.

The aerodynamic performance characteristics of QF-12 are presented in Fig. 8 as stage total pressure ratio and temperature rise efficiency versus percent of design inlet flow. These data were obtained with both the flight-type inlet (shown as open symbols) and the bellmouth inlet (shown as closed symbols). Also shown on this figure are the design point values of each of the parameters. The design flow and efficiency values were calculated before the mid-span damper was added to the rotor blade, so they do not reflect the blockage and loss normally associated with a damper. It is obvious that none of the three parameters quite met design values at design speed. Nearest the expected standard operating line the weight flow is low by about 7 percent, the efficiency is low by about 9 percentage points, and the pressure ratio reached only 1.56 rather than the design value of 1.6. It appears that by extrapolating the bellmouth data obtained near stall to design speed, the design pressure ratio might just be attained very close to stall. If the design values of weight flow and efficiency on Fig. 8 are adjusted for the effects of the damper, the measured value of flow is probably about 5 or 6 percent low and the efficiency about 7 percentage points low.

With limited aerodynamic instrumentation on the fan, it is not possible to detemine the exact source of the performance loss. Figure 9 indicates that the stage produces a rather low pressure rise near the hub and slightly above design value in the tip region. The efficiency is generally low over the full span. One test with the stators removed and the exit rakes realigned showed that essencially the same radial gradients are present which indicates that the problem is in the rotor. Without knowing such details as the radial variation of axial velocity into the rotor it is difficult to speculate on the reasons for the deficiencies in rotor performance, but it would seem probable that the high radial gradient of pressure ratio near the $t i p$, the high pressure ratio at the tip and the associated low efficiency could be the result of an unexpected normal shock over part of the rotor channel entrance region.

\section{Acoustic Performance}

Narrow-band analysis. The rotor source noise reduction concept embodied in the $Q F-12$ fan was expected to greatly reduce the multiple pure tones normally present at supersonic tip speeds. These tones in the forward noise spectra at integral multiples of the shaft rotative frequency, are most graphically seen on narrow-band spectra. Figure io displays such narrow-band spectra for QF-12 at $70^{\circ}$ from the inlet axis along the approximate standard operating line at several speeds. It is quite cbvious that $Q F-12$ does have a considerable MPT cintent in its spectrum at high tip speeds in contradiction to the predicted result, and these tones are quite audible when listening to the fan noise. However, the lowest speed at which the MPT noise is at all prominent is just below 80 percent of design at a tip relative inlet Mach number of approximate1y 1.25 . Conventional unswept fans which have been designed to be quiet will generally show the onset of prominent MPT noise at tip relative inlet Mach numbers in the range from approximately 0.9 to 1.0 . Even lower MPT thresholds are possible depending on a number of aeradynamic and blade design variables.

It is clear from this discussion of unswept rotors that the swept rotor has significantly raised the Mach number threshold for generation of MPT noise. Although the design calculations indicate a threshold much higher (the tip relative vach number is 1.75 when its normal component is 1.0 ), the beneficial effect of sweep on MPT noise is indicated.

The difference between predicted and measured MPT thresholds is probably related to several design limitations and aerodynamic deficiencies ir the fan design. First, the designer predicted the occurrence of weak conical shock systems at the rotor leading edge discontinuities (sweep reversal point and rotor tip) which were expected to produce a small amount of MPT noise at all supersonic tip speeds. In addition, the deficient aerodynamic performance could well be related to flow conditions in the entrance region of the interblade channels before the channel throat. Poor flow in this area of the blades could produce suction- 
surface shocks at separation points, for example. As noted previously, some of the radial performance variations could be speculatively related to such entrance region shocks. This situation could have been aggravated (perhaps even triggered) by the use of the essentially subsonic double-circular-arc rotor blade sections. It is also just possible that the part-span.damper could have diverted the adjacent streamines radially enough to decrease the effective sweep angle on one side and thus produce local leading edge shocks. Additionally, this design did not account for the adverse effect on sweep angle at some radii of a tapered rotor-blade planform which has its effective sweep angle at the quarter-chord line rather than at the leading edge. (8) Finally, the swept-edge concept as applied to an airplane wing requires some freedom for the streamlines to adjust spanwise, and the fan rotor cannot allow this near the walls and possibly near the damper. Whether or not this would be expected to have any real effect on the swept-edge performance in the fan is unknown.

One-third-octave analysis. Figure 11 presents one-third octave sound power level spectra for the QF-12 fan along the standard operating line at various speeds. The lower speeds, 50 and 70 percent of design, show no MPT content which typically appears in the frequency range centered from about one-tenth to one-half of blade-passage frequency. The highspeed spectra show very marked areas of MPT content centered at about $2 \mathrm{kHz}$. It is obvious from the narrow-band spectra of Fig. 10 that IPT noise fills the spectrum up to at least $25 \mathrm{kllz}$, but on a sound power basis it is most noticeabie in the one-third octave spectra in the area below blade-passage frequency. It can be seen that the 90 and 100 percent spectra have about the same MPT and blade-passage tone levels, while the 95 percent spectrum has noticeably more MPT noise and less blade-passage noise. Apparently as the speed is raised from 95 to 100 percent some tone generating mechanism changes drastically to shift the energy from IIPT to blade-passage tone noise, thereby altering the conventional trend of increasing MPT noise with increasing speed. This suggests the possibility that as the design aerodynamics are being approached (though never reached) the noise reduction concept is beginning to work as anticipated. Data at higher speeds were desired to evaluate this new trend but unfortunately the rotor blades were stress-limited to design speed.

Figures 12 and 13 present power spectra at 90 percent of fan design speed for the different operating lines with both flight-type and bellmouth inlets. While only the flight-type inlet data are presented in the remainder of the figures, here the bellmouth inlet data are presented because of the additional operating line quite close to stall. In general, raising the operating line, and thus the fan loading and pressure ratio, raises the MPT noise in the 1 to $5 \mathrm{kHz}$ range. Note, though, that with both inlets the standard operating line has less MPT noise than the below-standard line. At speeds of 95 and 100 percent of design, however, the MPT noise increases in orderly fashion with pressure ratio as the operating line is changed. This suggests again that subtle differences in rotor-entrance aerodynamics can have a quite measurable effect on MPI noise, and thus on the apparent validity of the swept-rotor noise reduction concept.
Tests with inlet flow control device. A series of tests using the inlet flow control device of Figs. 5 and 6 was intended to determine the sensitivity of the QF-12 fan blade-passage tone noise to inflow turbulence, and in addition determine if any such sensitivity exists in the MPT noise. A comparison of sound power spectra at 80 percent of design speed which is typical of spectra with and without the inlet flow control device in shown in Fig. 14. There is no obvious effect of the inlet flow control on either blade-passage noise or MPT noise at this supersonic speed. The fact that MPT noise is not altered by the inlet flow control device apparently indicates that the shock generation process is insensitive to the small flow perturbations on the blade edge and surfaces due to turbulence. This contrasts somewhat with the results of Ref. 6, possibly because the present results are obtained at a higher Mach number level.

A comparison of blade-passage tone sound power level with and without the inlet flow control device is shown in Fig. 15 over the full range of speed. This figure indicates that at tip speeds below that at which shock effects (i.e., MPT noise) begin to predominate, the inlet flow control device does reduce blade-passage tone noise some 2 to $4 \mathrm{~dB}$. It has no obvious effect at higher speeds. The azimuthal effect on blade-passage tone sound pressure level is shown in Fig. 16 with and without the inlet flow control device. Figure 16 (a) shows that at a speed below the onset of shock effects the blade-passage tone sound pressure level is essentially constant around the inlet arc. However, above shock onset, Fig. 16(b) shows that the bladepassage tone sound pressure level is reduced noticeably between the inlet axis and $60^{\circ}$ (except on the axis), and increased between angles of $60^{\circ}$ and $90^{\circ}$ with the inlet flow control device. The net effect on sound power level at this speed was shown on Figs. 14 and 15 to be about zero. Because no effect of the inlet flow control device has teen shown on tone levels at high speeds, the comparisons to follow will be made using data obtained without the device.

Sound Power Comparison of QF-12 and Other Fans

Comparison with JT8D Refan. The QF-12 fan was acoustically tested in a facility in which a model of the JT8D Refan had been previously tested as reported in Ref. 5. The Refan model, a modern, quiet fan, is the same size as $Q F-12$, has nearly the same pressure ratio (1.67 vs. 1.60$)$, slightly higher flow $(35.0 \mathrm{~kg} / \mathrm{sec} v s .31 .2)$, and nearly the same tip speed ( $488 \mathrm{~m} / \mathrm{sec}$ vs. 480 ). While the Refan has inlet guide vanes it is otherwise quite similar to QF-12 but with conventional unswept rotor blading. The fact that the Refan is aerodynamically so similar to $Q F-12$ and was tested in the same facility with the same flight-type inlet makes it a good standard for acoustic comparisons. The differences between these two fans are relatively small but could become acoustically significant at the highest speeds. The Refan did attain its design aerodynamics where QF-12 did not. Futhermore, the Refan inlet guide vanes were designed to raise the rotor hub relative inlet Mach number and lower somewhat the rotor tip relative inlet Yach number. This lowering of the tip relative Mach number would slightly weaken the normally strong leading edge shocks and thus would tend to lessen somewhat the 
MPT noise generation. In addition the presence of the guide vanes constitutes a flow area blockage which locally raises the already high axial Mach number and could therefore possibly attenuate the forward propagation of sound at high speed relative to the non-IGV QF-12 noise propagation. However, even with these differences the two fans are similar enough to warrpnt a comparison of their noise output.

Figures 17 and 18 present direct comparisons between the two fans of overall sound power level and blade-passage tone one-third octave sound power level respectively as functions of fan speed. The overall power levels for the two fans are nearly identical through 90 percent of design $f$ an speed, but at higher speeds $Q F-12$ is some $4 \mathrm{~dB}$ higher because of a large jump in noise between 90 and 95 percent speed. The blade-passage tone noise (Fig. 18) is about the same for the two fans at the lower speeds, but above 80 percent speed, QF-12 is some 5 to $9 \mathrm{~dB}$ noisier than Refan. It is significant that between 90 and 95 percent speeds the overall power level of $Q F-12$ rises while the blade-passage tone level decreases, with these trends being sharp$1 y$ reversed between 95 and 100 percent speeds. This is related to the sharp peak in MPT generation at 95 percent speed and equally sharp dropoff at 100 percent speed shown on Fig. 11 .

Comparison with 4 high-speed fans. In addition to the Refan just discussed, there are several other modern high-speed quiet fans for which noise data are available to compare with those of $Q F-12$. Appropriate design parameters for these fans are given in Table I. Fan C from the NASA Quiet Engine Program is a conventional high speed fan designed to be as quiet as possible within the framework of conventional acrodynamic design criceria. It was built and tested in full engine size, and the noise data are reported in Ref. 9.

Fan C - Mod VIII was an improvement of fan C with the rotor blade very carefully reshaped to swallow the inlet shock at 90 percent speed (the takcoff speed) rather than at 100 percent speed as fan $C$ had been designed, yet still at least retain the efficiency of the original fan $c$. The basic intent was to reduce the MPT noise at takeoff with the altered shock structure. In this it was quite successful, although at the expense of noticeably increased blade passage tone noise. This fan was built and cested in about half the size of fan $C$, and its noise characteristics are reported in Ref. 10.

The General Electric GE-ATT fan was of about the same tip speed as the other fans under consideration here, but it had a somewhat higher pressure ratio and design specific inflow. It was designed with as many quieting features as possible includIng swallowed shocks at takeoff speed. It was built and tested in about half scale, and the noise data are reported in Ref. 11 .

The Pratt and Whitney JT8D Refan has been discussed earlier. Its most significant difference from the other fans in this comparison was the use of inlet guide vanes. Acoustic data for this model fan are reported in part in Ref. 5, and in part are unreported. The fan $\mathrm{C}$ and GE-ATT inlet noise data were obtained with bellmouth fan inlets, while the other three fans used modified flight-type inlets. The data for all five fans have been corrected to a design thrust level equal to that of fan $C$ for purposes of comparison. This was accomplished by 3 dding to the model sound power levels a number of decibels equal to $10 \mathrm{log}$ of the ratio of $f a n c$ design thrust to the model fan design thrust. The model spectra were then shifted down in frequen:y (to the nearest one-third octave) by the square root of the ratio of fan $C$ design thrust to the model fan thrust.

Inlet sound power spectra for all five of the fans at 90 percent of their individual design speeds (to represent the noise expected at takeoff) are shown on Fig. 19. For clarity of presentation the spectra are divided into two separatelypresented groups, each of which contains the QF-12 spectrum. In the MPT range below about $1600 \mathrm{~Hz}$ fan $C$ and the GE-ATT fan are seen to be much hizher in MPT production than the other fans. Fan $C$ Mod VIII obviously met its design goal of reducing the MPT noise of $\mathrm{fan} C$ by lowering it some 8 to 10 $\mathrm{dB}$. However, this reduction came at the expense of a considerabie increase in blade-passage noise. This had been shown experimentally in Ref. 10 to be a consequence of each of the various modifications made to the fan $C$ design to lower the MPT noise at cakeoff speed. The Refan and $Q F-12$ are seen on Fig. 19 (a) to be nearly equal in MPT production, with QF-12 being slightly the lower of the two. QF-12 and fan C - Mod VIII are also nearly equal with QF-12 being somewhat poorer below about $600 \mathrm{~Hz}$.

An attempt was made to quantify the MPT content in the spectra for the five fans by logarithmically adding the one-third octave sound power levels in the portions of the spectra below the blade-passage frequency where the MPT content appeared dominant. While the resulting numbers are not the true SPT noise, they do represent a reasonable and consistent "figure of merit" for MPT noise. The results should be a function of tip relative inlet Mach number, but because insufficient information existed to calculate this number for all fans, the results are shown on Fig. 20 as a function of fan speed. For this group of $f$ ans with similar design flows and tip speeds, the fan speed is a satisfactory correlating parameter. This figure clearly shows QF-12 and fan C - Mod VIII to be noticeably lower than the others in MPT noise a: speeds of 90 percent and below. Of these two fans, fan C - Mod VIII is equally clearly the better.

The sound power levels of the five fans are compared on a current correlation of the sound power from modern, quiet low-tip-speed fans (Réf. 12). This correlation presents the thrust-corrected sound power level as a function of total pressure rise ratio, and it correlated the noise of many low speed fans within $\pm 2.5 \mathrm{~dB}$. Note, however, that the correlation was developed for total fan sound power, and the high speed fan data to be presented on this correlation are for forward noise only. In Fig. 21 these data are presented with the correlation.

All of the fans have low speed noise trend: which follow the correlation well. At the approximate speed where MPT noise appears the data curres rise much more steeply than the correlation, and at high speeds the fans for which such data are available (QF-12, Refan, and GE-ATT) all show a marked dropof $f$ in noise. This latter effect is probably an attenuation due to the high axial Mach numbers at the fan inlet. The GE-ATT fan shows the most spectacular dropoff due to having the highest de- 
sign specific inlet flow and thus the highest axial Mach number. It is also the only fan shown for which the final data point presented was obtained at a speed over design (106 percent of design).

Fan $C$ and GE-ATT are seen on Fig. 21 to be the nolstest in the MPT range below the point where inlet Mach number attenuation becomes evident. The other three fans are noticeably better and are about equivalent. It appears significant that QF-12, despite aerodynamic problems which evidently negated some of the value of the swept-edge concept, is roughly equivalent in noise production in the MPT range to a fan specifically developed to reduce MPT at the expense of a large increase in bladepassage tone noise ( $f$ an $C$ - Mod VIII), and to a highly developed fan using inlet guide vanes to reduce the MPT-generating tip inlet relative Mach number (Refan). The forward sound power of these three high-speed fans falls within the correlating band for total low-speed fan noise, and inasmuch as these fans are expected to be dominated by their forward noise it appears that even their total noise could fall within the band. This good acoustic performance of $h$ igh-speed fans was unexpected from the preliminary results of Ref. 12 which included only $F$ an $C$.

\section{Perceived Noise Comparison of $Q F-12$ and Other Fans}

A perceived noise level comparison between QF-12 and the Refan model, both scaled to Refan engine thrust levels is presented in Fig. 22. $Q F-12$ is seen to be somewhat lower in perceived noise at low fan speeds and somewhat higher at high speeds. At the takeof $f$ fan speed of 90 percent of design, at which the two fans have almost identical percelved noise, an azimuthal plot of perceived noise on a 30.5 meter sideline is given on Fig. 23. The two fans have much the same arimuthal projection of noise with $\operatorname{Refan}$ beaming its noise slightly more toward the inlet axis.

The takeoff (90 percent speed) maximum sideline perceived noise level was calculated for each of the five high-speed fans described above and plotted on a correlation described in Ref. 12 of thrust-corrected perceived noise level. These calculations, shown on Fig. 24, indicate that fan C and fan C - Mod VIII are both above the correlation band, the latter only because of its high bladepassage tone level. The other three fans fall well wi thin the band. Again QF-12 is among the best of the fans even with the aerodynamic problems which appeared to prevent it from gaining full benefit frow the swept-edge acoustic concept.

\section{Concluding Remarks}

A series of experiments were conducted to assess the overall aerodynamic and inlet acoustic - performance of an aircraft fan designed with a swept leading edge on the rotor blades. The edge was designed to be "subsonic" to minimize the production of inlet shock systems and thus minimize the generation of multiple pure tone (MPT) noise.

The aerodynamic performance parameters of the fan did not reach design values, with radial distributions of some parameters being quite different from design. It was expected that this could have been associated with unanticipated shocks near the rotor tip. Such shocks were also indicated by the presence of MPT noise in the inlet spectra.

The threshold of the MPT noise occurred at an inlet tip relative Mach number of about 1.25 , considerably above the more normal range of perhaps 0.9 to 1.0 expected from conventional fan rotor blades. The MPT noise rises rapidly from its threshold to 95 percent of design fan speed and then decreases quite markedly at design speed. It seems evident that the details of rotor entrance flow conditions have a strong influence on MPT noise production by this fan, and it would seem equally evident that proper aerodynamic diagnosis and redesign of the rotor could probably lower the MPT nolse production and raise its threshold.

When compared with four other high-speed quiet fans, the swept rotor fan produced less MPT noise than all but one, and that one had obtained low MPT noise at the expense of greatly increased blade-passage tone noise. The best three of these high-speed fans, the swept rotor fan among them, produced forward sound power which fell well within the band of total levels of modern quiet low speed fans on a correlation of such noise. On the basis of maximum sideline perceived noise, the swept rotor fan was again among the best three, all of which are within the correlation band of such noise for modern, quiet low speed fans.

For the first build of a fan which was very difficult to design, and for which no firm detailed design rules were available, this swept-rotor fan must be considered fairly successful. It did not fulfill its highest acoustic expectations, but did show an improvement over conventional designs. The source of the performance deficiencies is apparently in the rotor inflow aerodynamics, and a more detailed investigation of those aerodynamics would be expected to indicate areas for significant performance improvement, both aerodynamic and acoustic.

\section{References}

1. Bliss, D. B., Hayden, R. E., Murray, B. S., and Schwar, P. G., "Design Considerations for a Novel Low Source Noise Transonic Fan Stage," AIAA Paper 76-577, July 1976.

2. Hayden, R. E., Bliss, D. B., Murray, B. S., Chandiramani, K. L., Smullin, J. I., and Schwaar, P. G., "Analysis and Design of a High Speed, Low Noise Aircraft Fan Incorporating Swept Leading Edge Rotor and Stator Blades," Bolt, Beranek and Newman, Inc. Cambridge, MA, BBN-3332, Feb. 1978. (NASA CR-135092)

3. Jones, R. T., "Wing Planforms for High-Speed Flight," NACA Report 863, 1947.

4. Bliss, D. B., "Method of, and Apparatus for, Preventing Leading-Edge Shocks and ShockRelated Noise in Transonic and Supersonic Blades and the Like," U.S. Patent $3,989,406$, Nov. 2, 1976.

5. Wazyniak, J. A., Shaw, L. M., and Essary, J.D., "Characteristics of an Anechoic Chamber for Fan Nolse Testing," NASA IM X-73555, 1977. 
6. Woodward, R. P., Wazyniak, J. A., Shaw, L. M., and Mackinnon, M. J., "Effectiveness of an Inlet Flow Turbulence Control Device to Simulate Flight $F$ an Noise in an Anechoic Chanber," NASA TM-73855, 1977.

7. Montegani, F. J., "Some Propulsion System Noise Data Handling Conventions and Computer Programs Used at the Lewis Research Center," NASA IM X-3013, 1974.

8. Corning, G., Supersonic and Subsonic, CTOL and VTOL, Airplane Design, 4th ed, University of Maryland, College Park, MD, 1976.

9. Montegan1, F. J., Schaefer, J. W., and Schmiedlin, R. F., "Noise Generated by Quiet Fans, III - Fan C," NASA TM X-3360, 1976.

10. Jutras, R. R., and Kazin, S. G., "Acoustic Results of Supersonic Tip Speed Fan Blade Modifications," General Electric Co., Cincinnati, OH, R73AEG407, 1974. (NASA CR121233)

11. Jutras, R. R., "Single Stage, Low Noise, Advanced Technology Fan, Volume V, Fan Acoustics, Section 2: One-Third Octave Data Tabulations and Selected Narrowband Traces," General Electric Co., Evendale, OH, R75AEG431, 1976. (NASA CR-134895)

12. Heidmann, M. F., and Feiler, C. E., "Noise Comparisons from Full-Scale Fan Tests at NASA Lewis Research Center," AIAA Paper 73-1017, oct. 1973. Also NASA TM X-68289, 1973.

\section{TABLE I}

\begin{tabular}{lccc}
\hline Fan & $\begin{array}{c}\text { Tip speed, } \\
\mathrm{m} / \mathrm{sec}\end{array}$ & $\begin{array}{c}\text { Tip diameter, } \\
\mathrm{m}\end{array}$ & $\begin{array}{c}\text { Pressure } \\
\text { ratio }\end{array}$ \\
\hline QF-12 & 480 & 0.498 & 1.6 \\
Fan C & 472 & 1.73 & 1.6 \\
Fan C - Mod VIII & 472 & 0.914 & 1.6 \\
GE-ATT & 503 & 0.904 & 1.8 \\
JT8D Refan & 488 & 0.508 & 1.67 \\
\hline
\end{tabular}




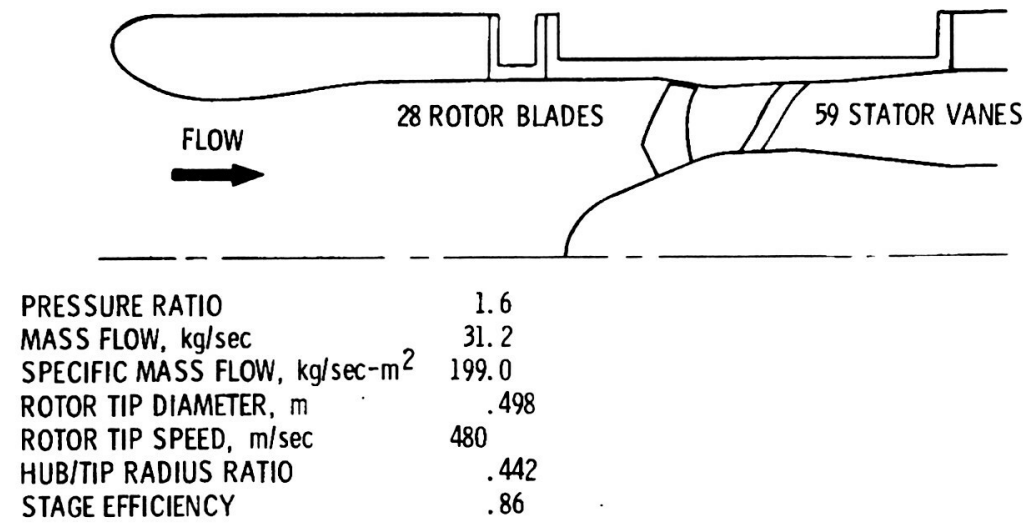

Figure 1. - Schematic cross-sectional view of fan QF-12 and table of design characteristics.

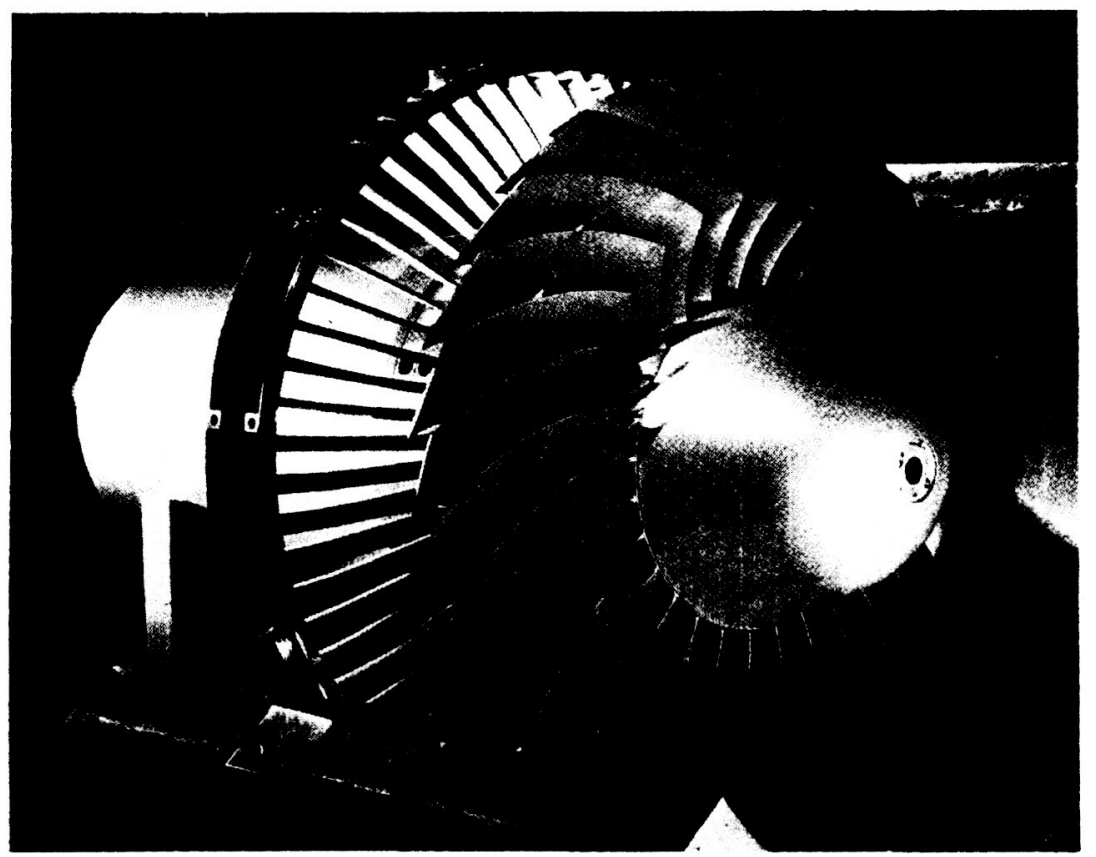

Figure 2. - QF-12 Fan. 


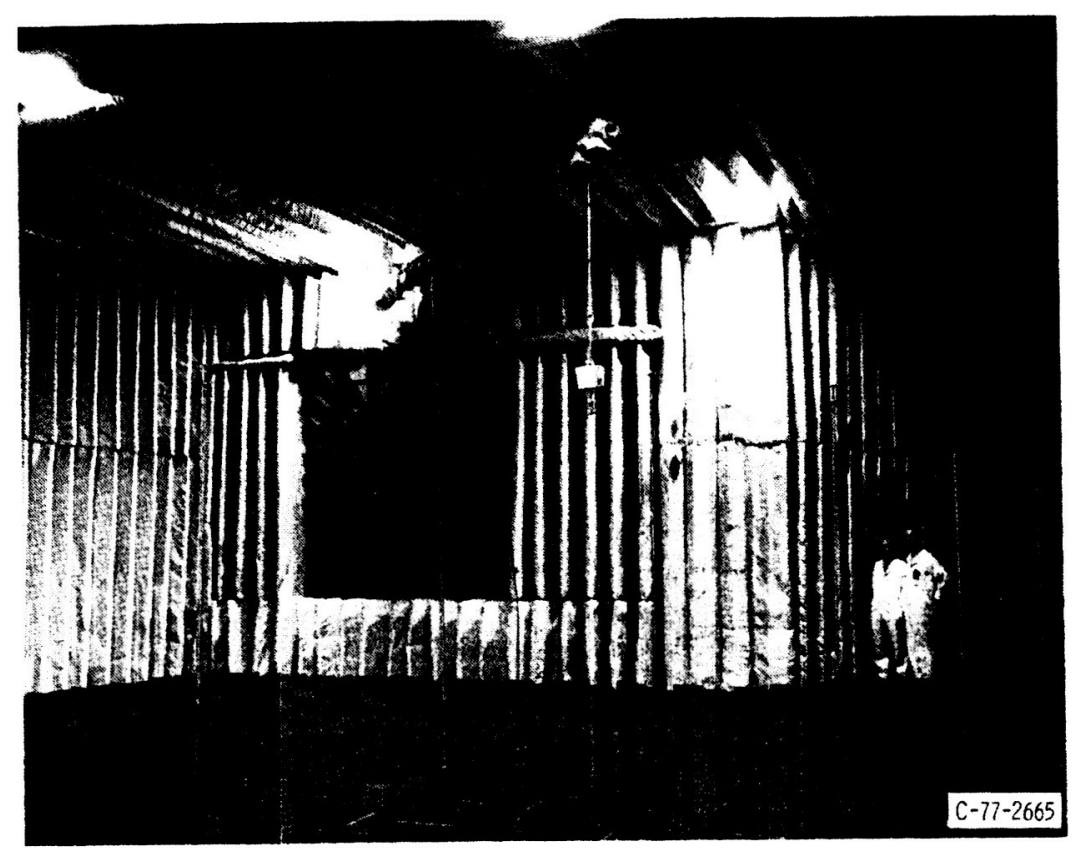

Figure 3. - QF-12 Fan in acoustic test facility. 


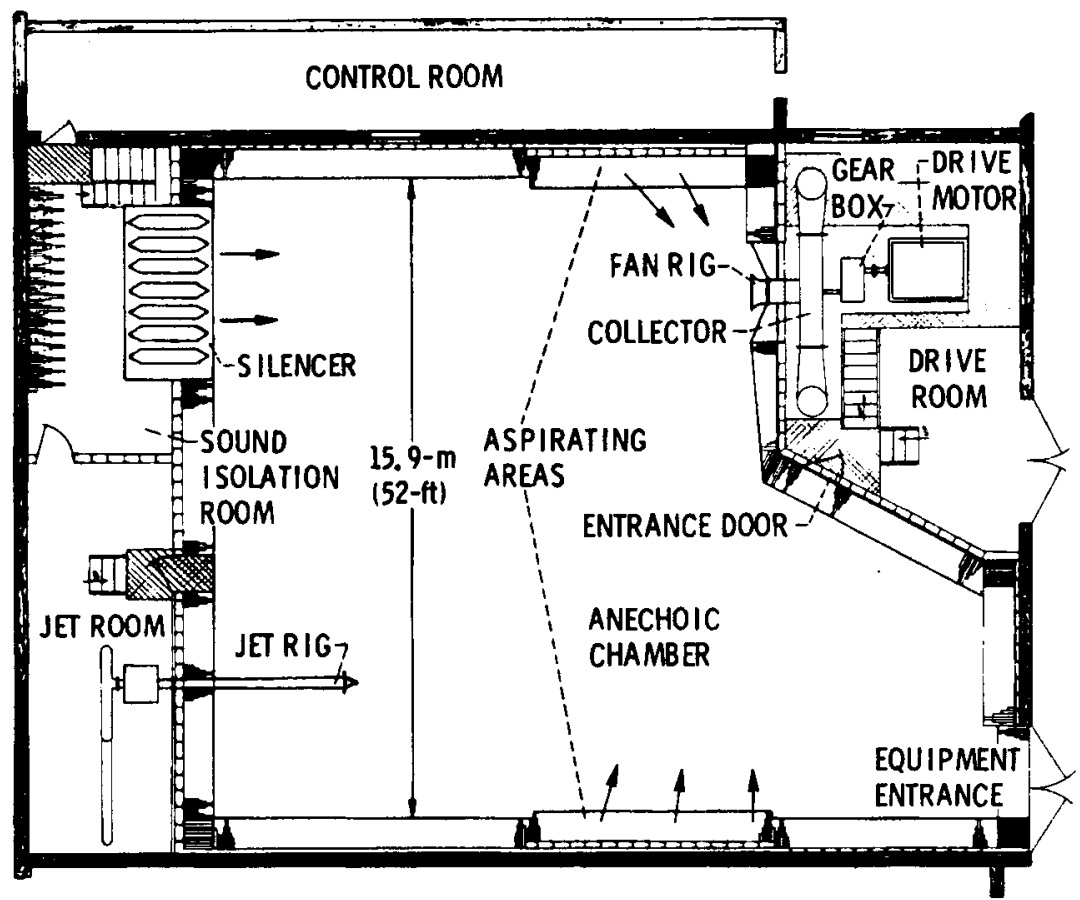

(a) NOISE FACILITY FLOOR PLAN.

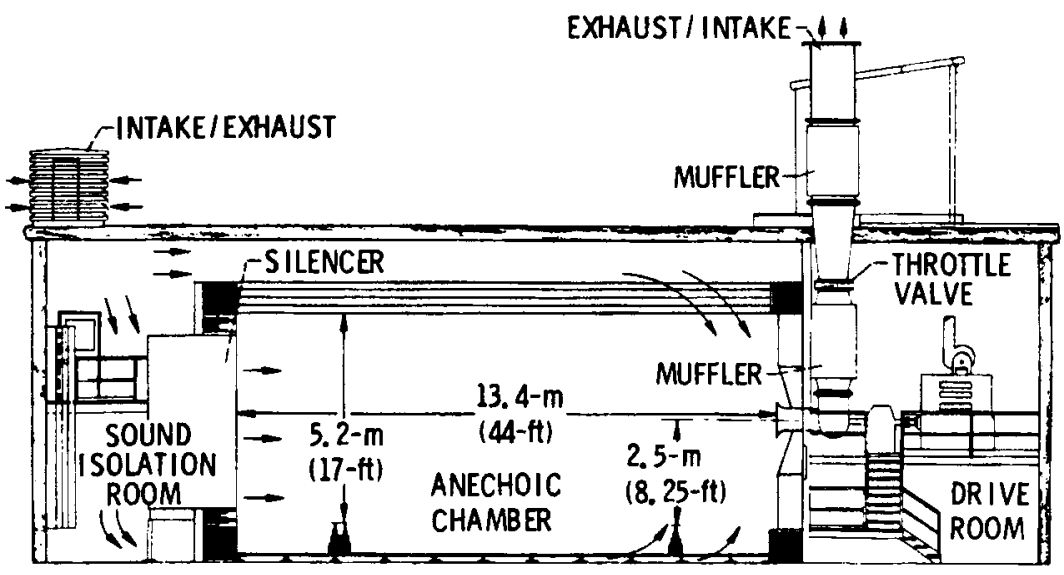

(b) NOISE FACILITY ELEVATION.

Figure 4. - Anechoic chamber. 


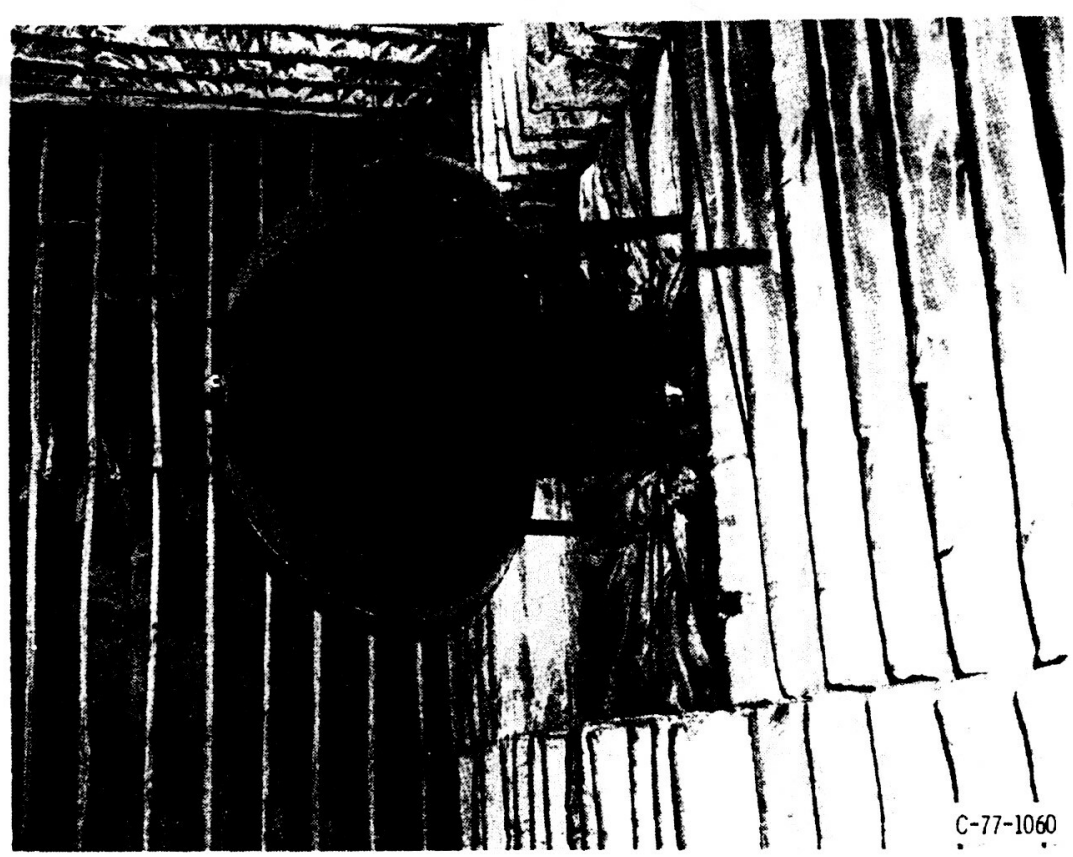

Figure 5. - Inlet flow control device installed on research fan in anechoic chamber.

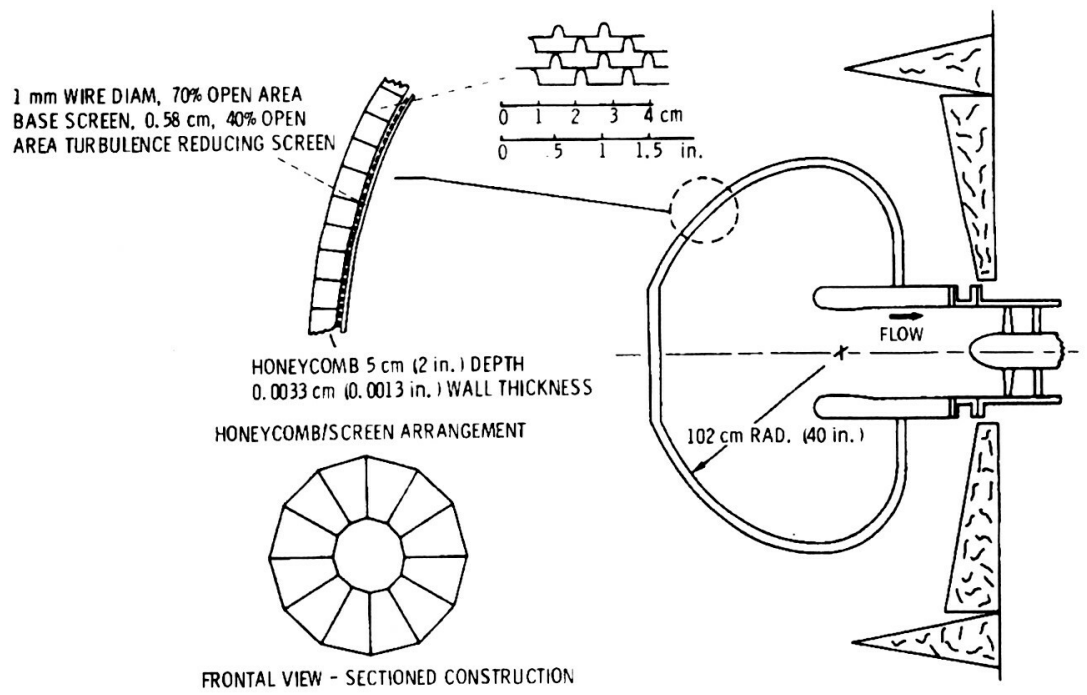

Pigure 6. - Inlet flow control device. 


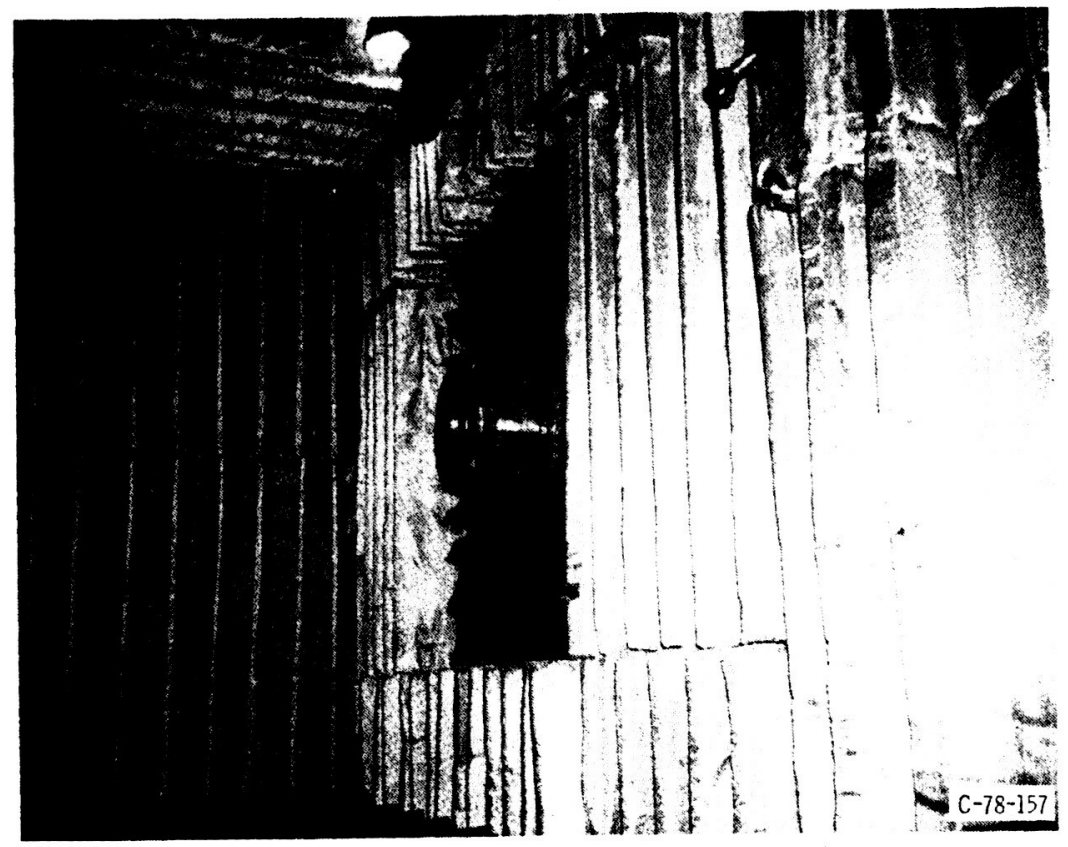

Figure \%. - Bellmouth inlet on QF-12 fan.

wi
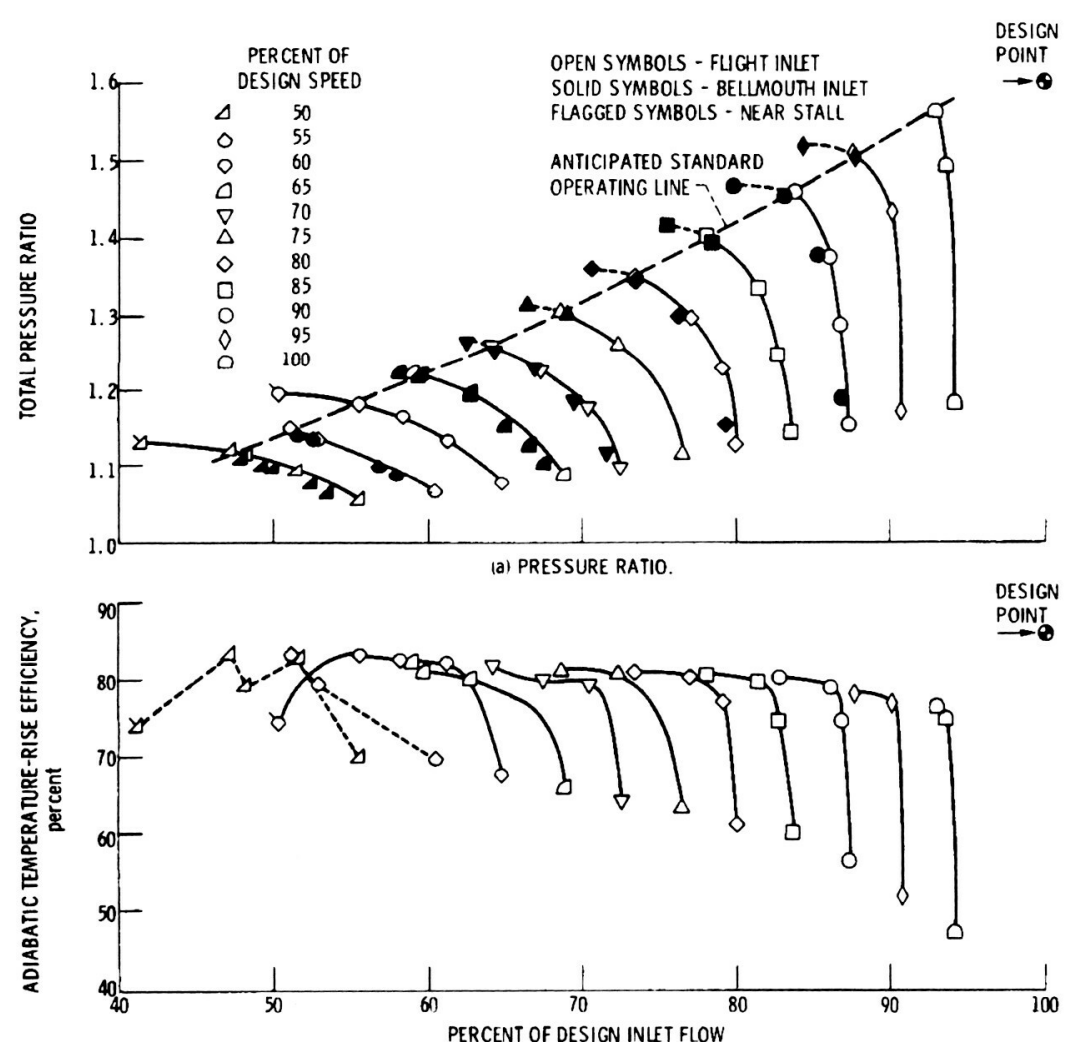

(b) EFFICIENCY

Figure 8. - Overall aerodynamic performance of fan Qf- 12 . 


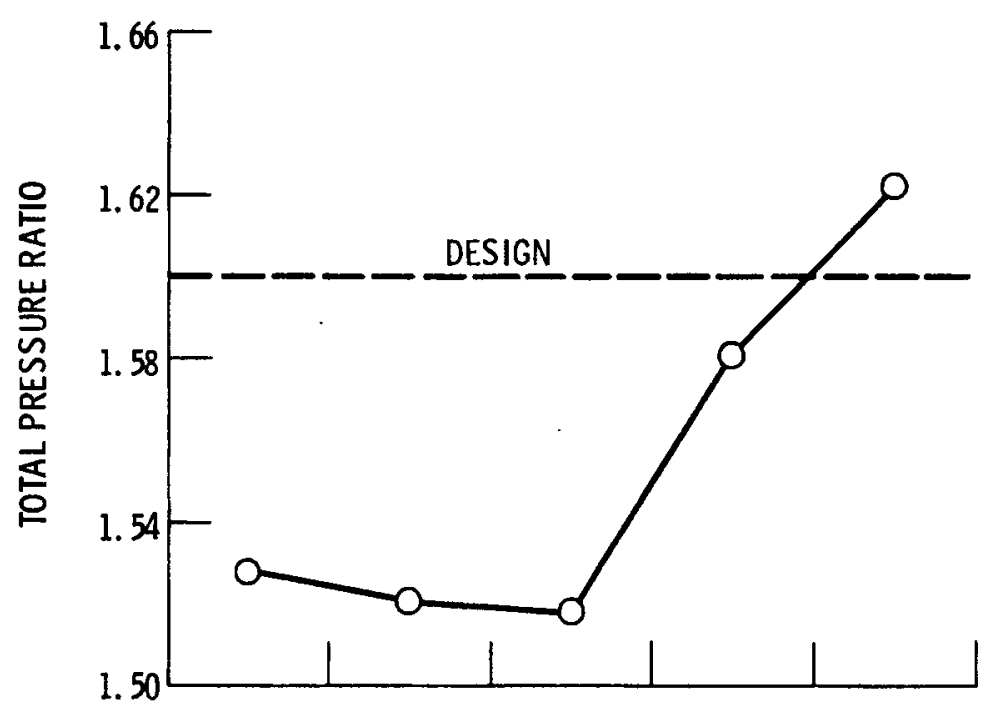

(a) PRESSURE RATIO.

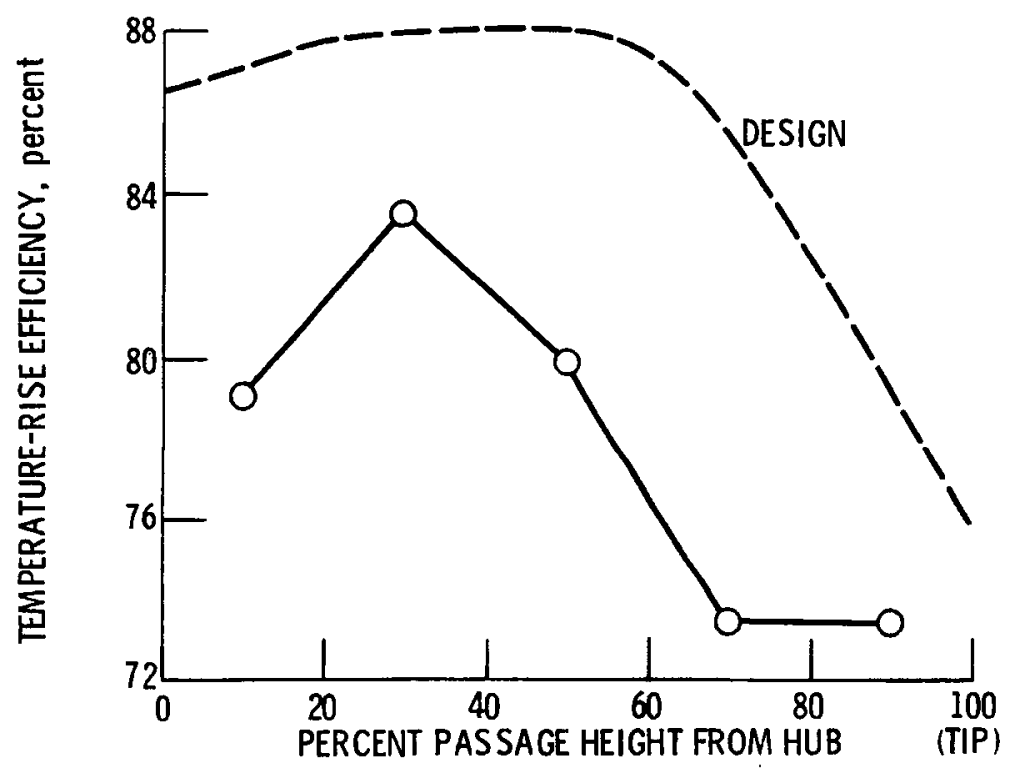

(b) EFFICIENCY.

Figure 9. - Radial variation of stage efficiency and pressure ratio on standard operating line at 100 percent of design speed. 


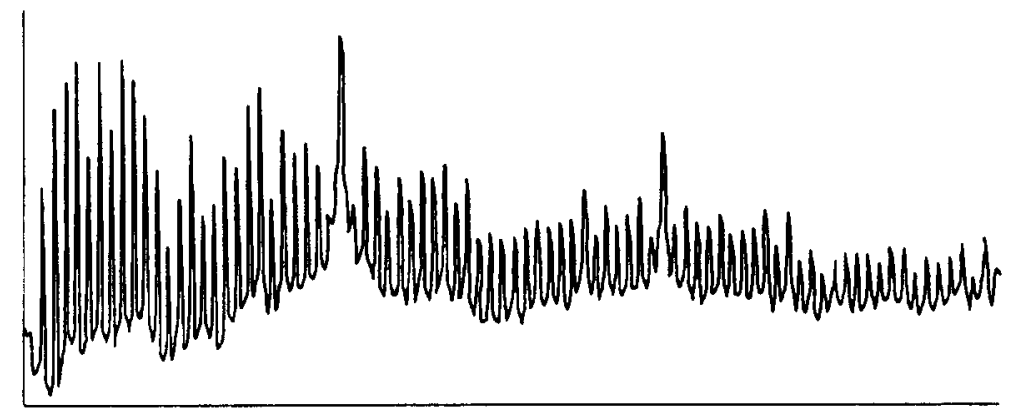

(a) 100 percent SPEED.
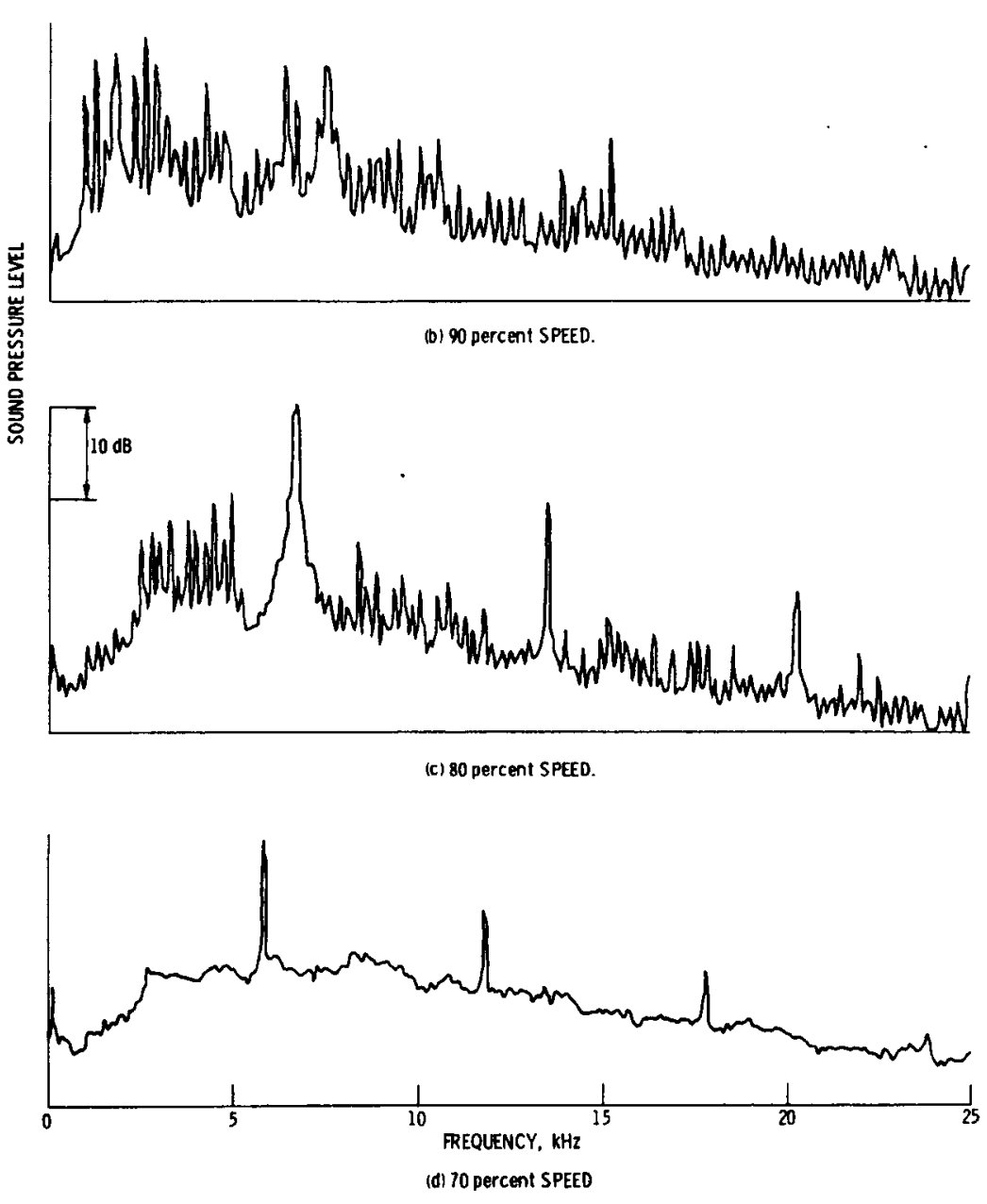

Figure 10. - Narrow-band spectra of $Q F-12$ on standard operating line at $70^{\circ}$ from fan inlet axis. 


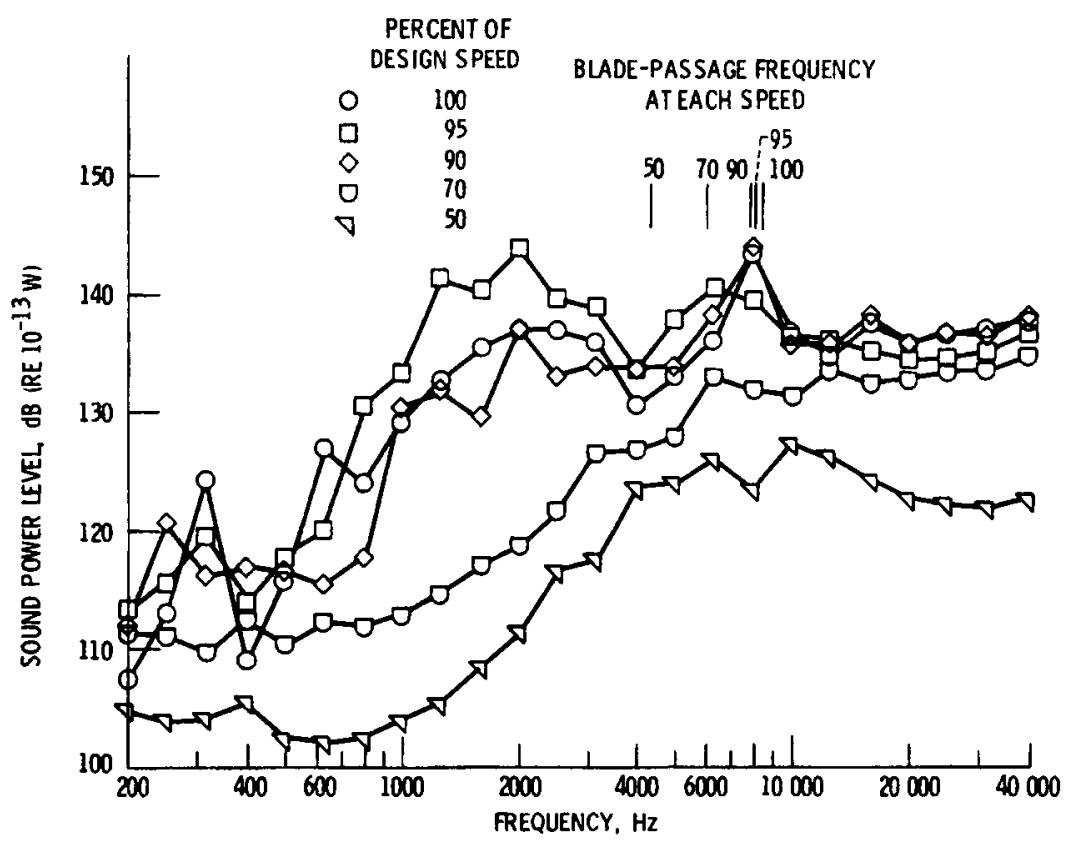

Figure 11. - Effect of fan speed on QF-12 inlet power spectrum on standard operating line.

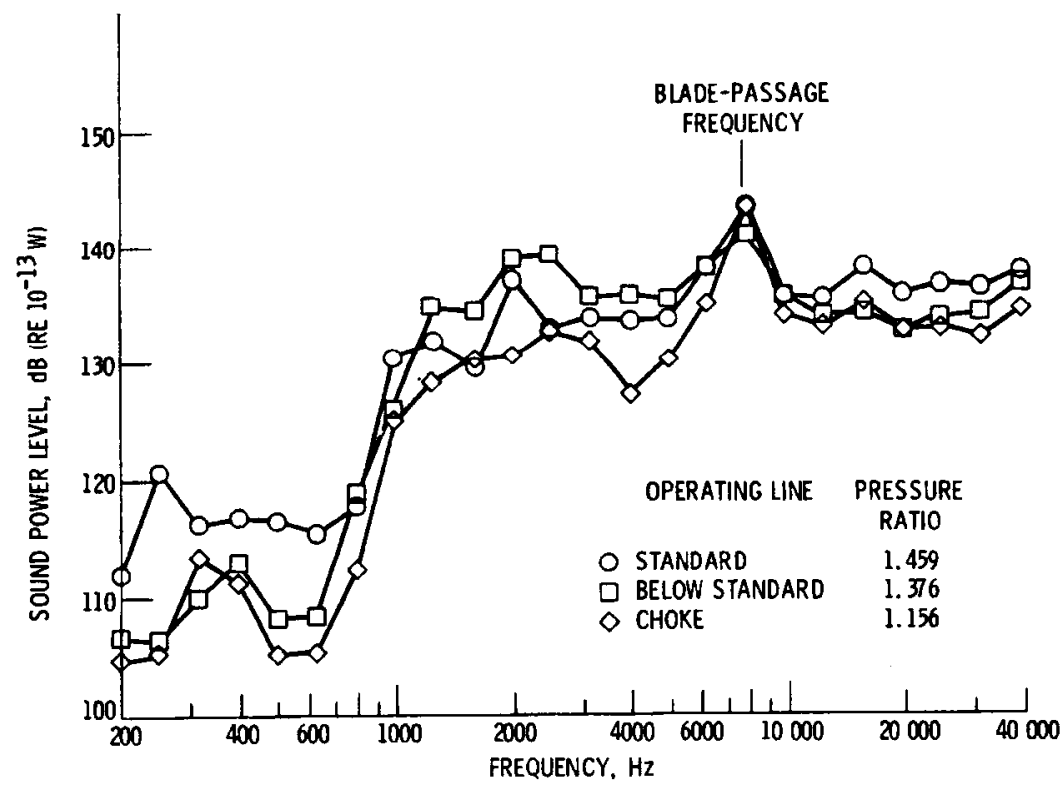

Figure 12. - Effect of cperating line variation on QF-12 inlet power spectrum at 90 percent of design fan speed with flight-type inlet. 


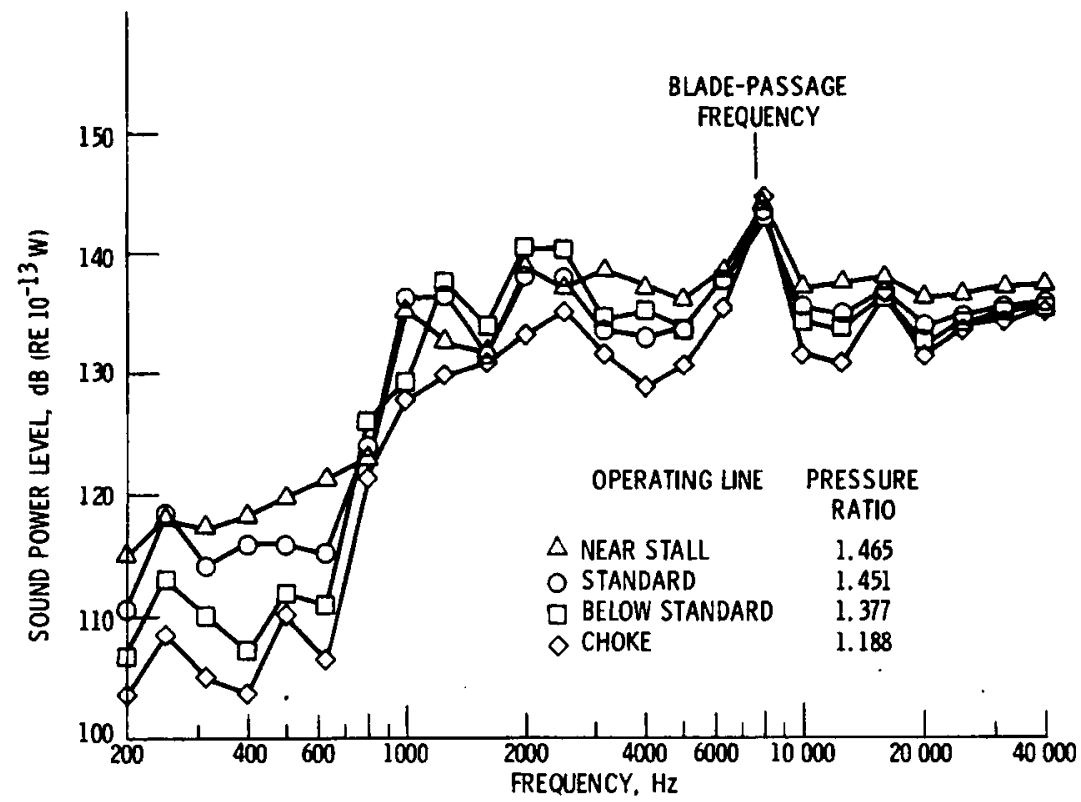

Figure 13. - Effect of operating line variation on QF-12 inlet power spectrum at 90 percent of design fan speed with belimouth inlet.

is

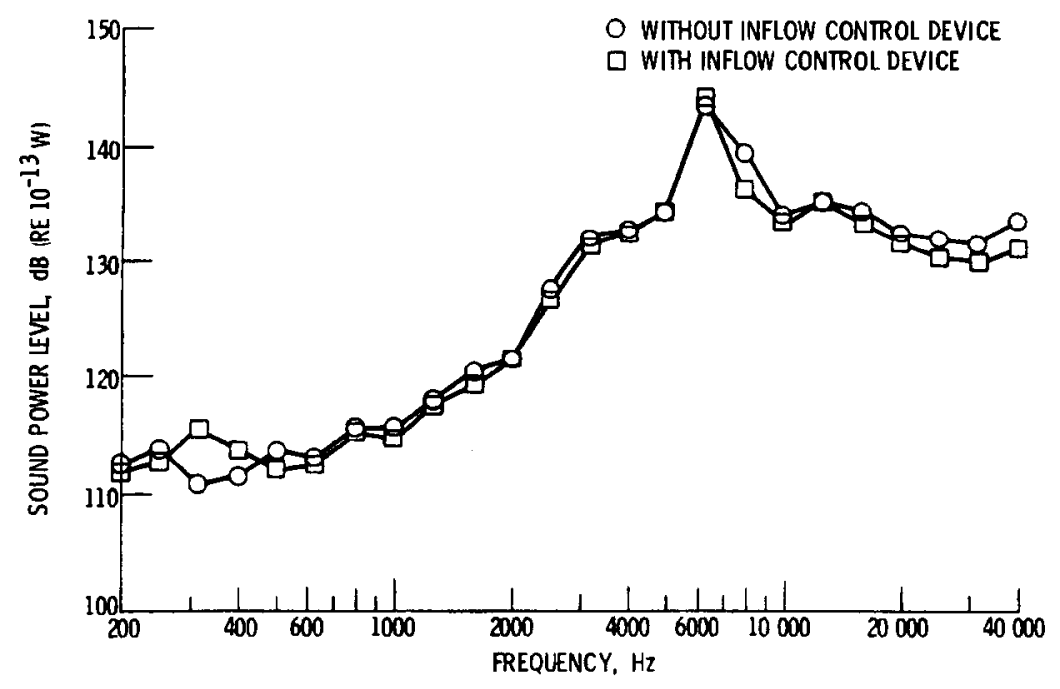

Figure 14. - Effect of inflow control device on QF-12 noise at 80 percent of design fan speed on standard operating line. 

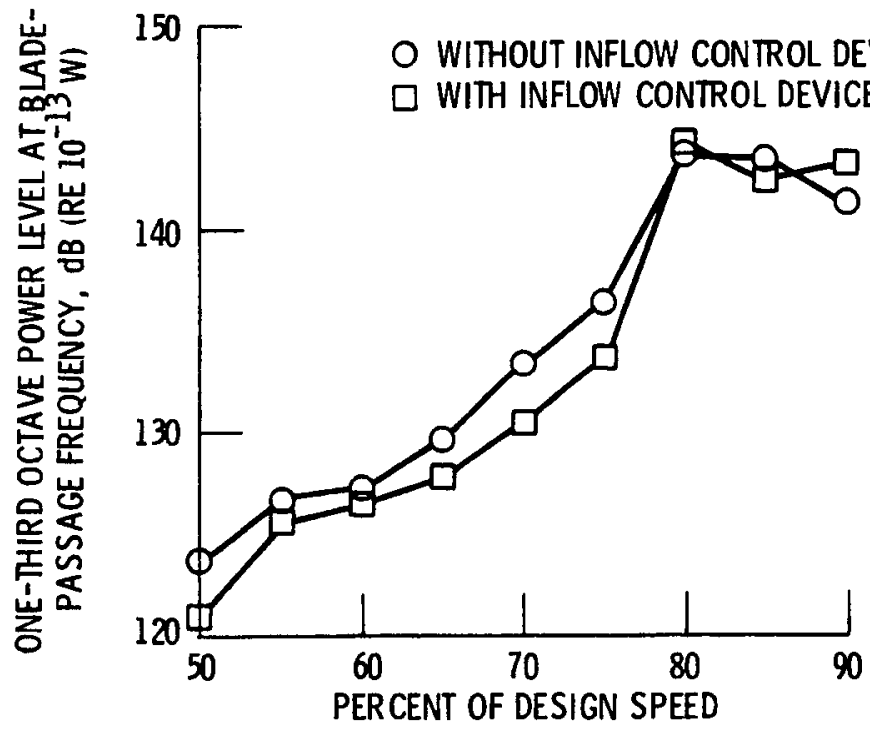

Figure 15. - Effect of inflow control device on QF-12 blade passage power level with fan speed on standard operating line. 


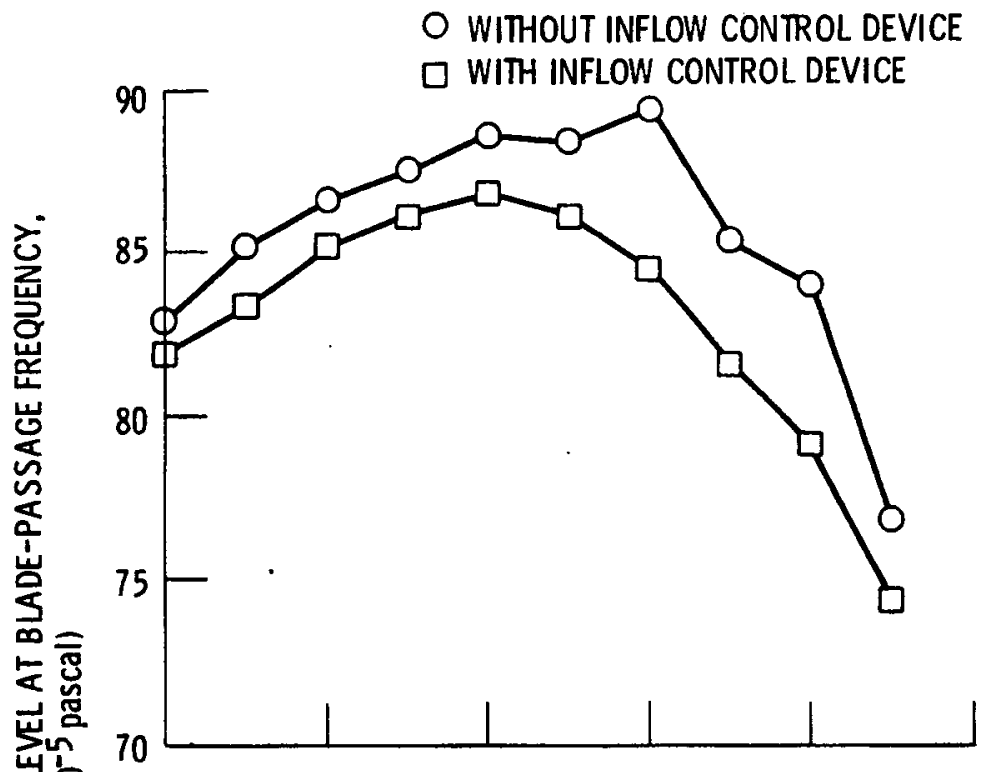

(a) 70 percent SPEED.

殅

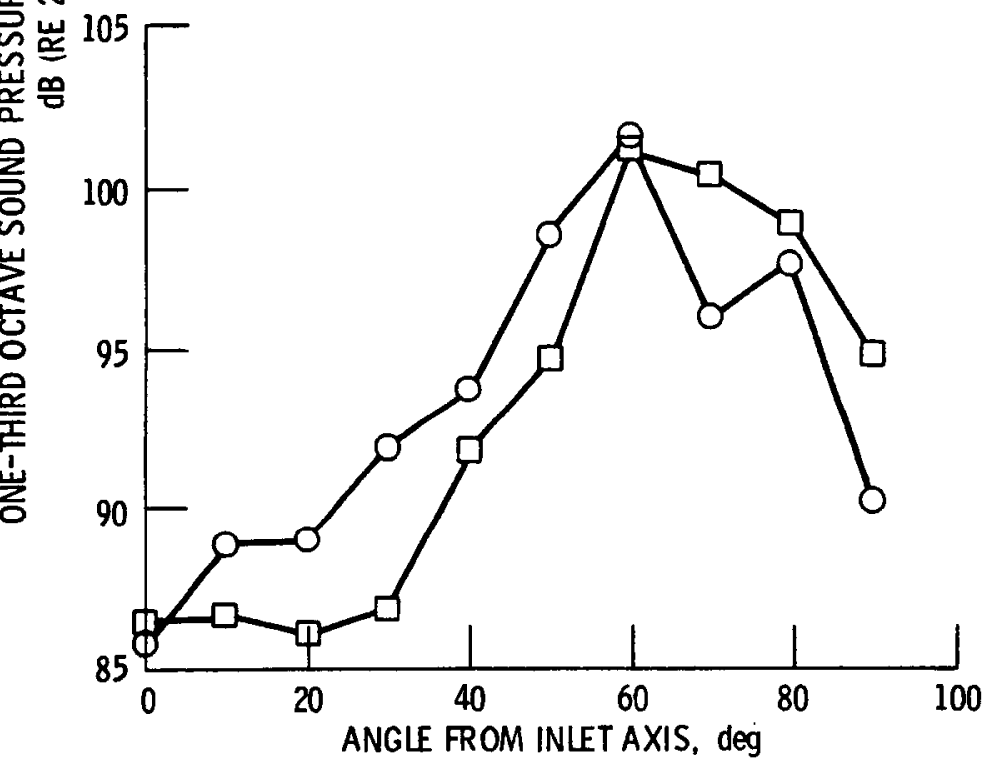

(b) 80 percent SPEED.

Figure 16. - Azimuthal effect of inflow control device on QF-12 blade passage tone at a fixed fan speed. 


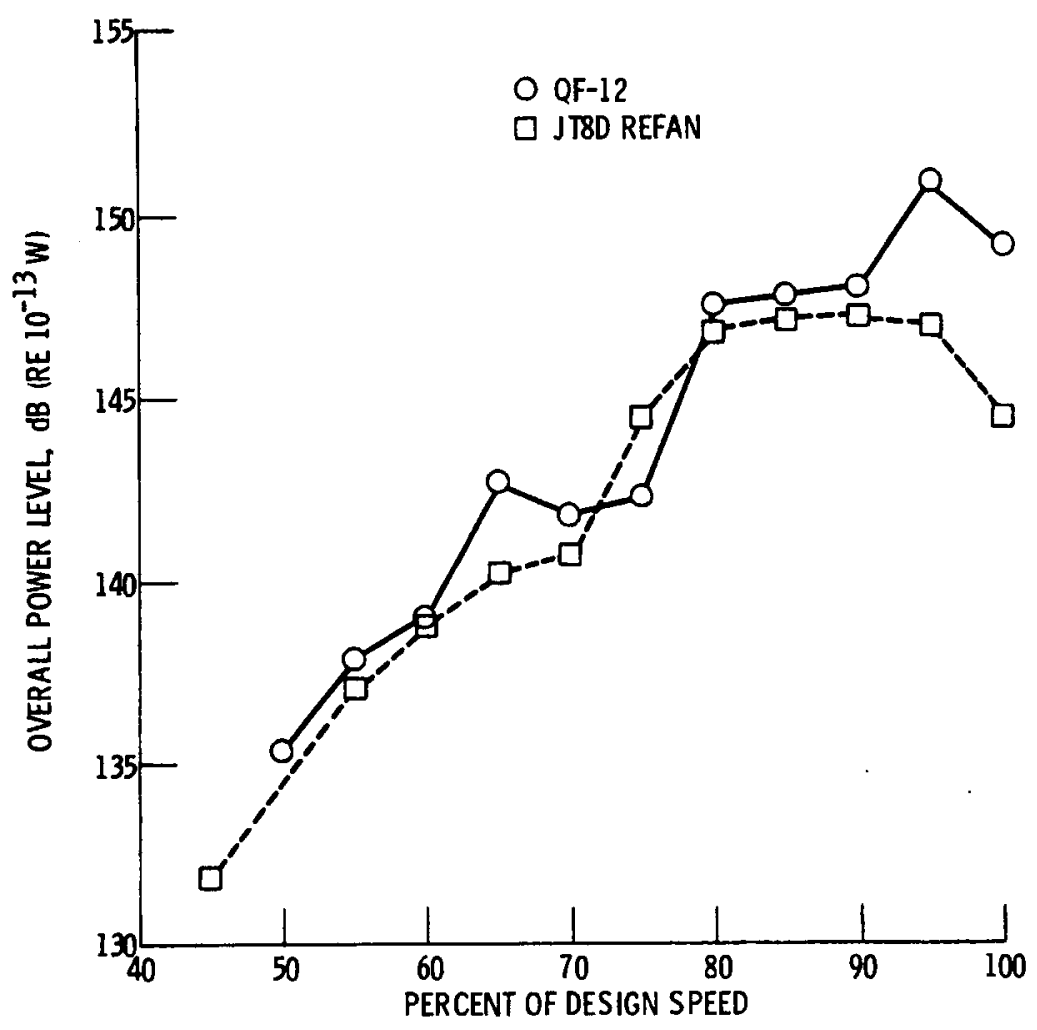

Figure 17. - Comparison of QF-12 and JT8D refan power levels on standard operating lines.

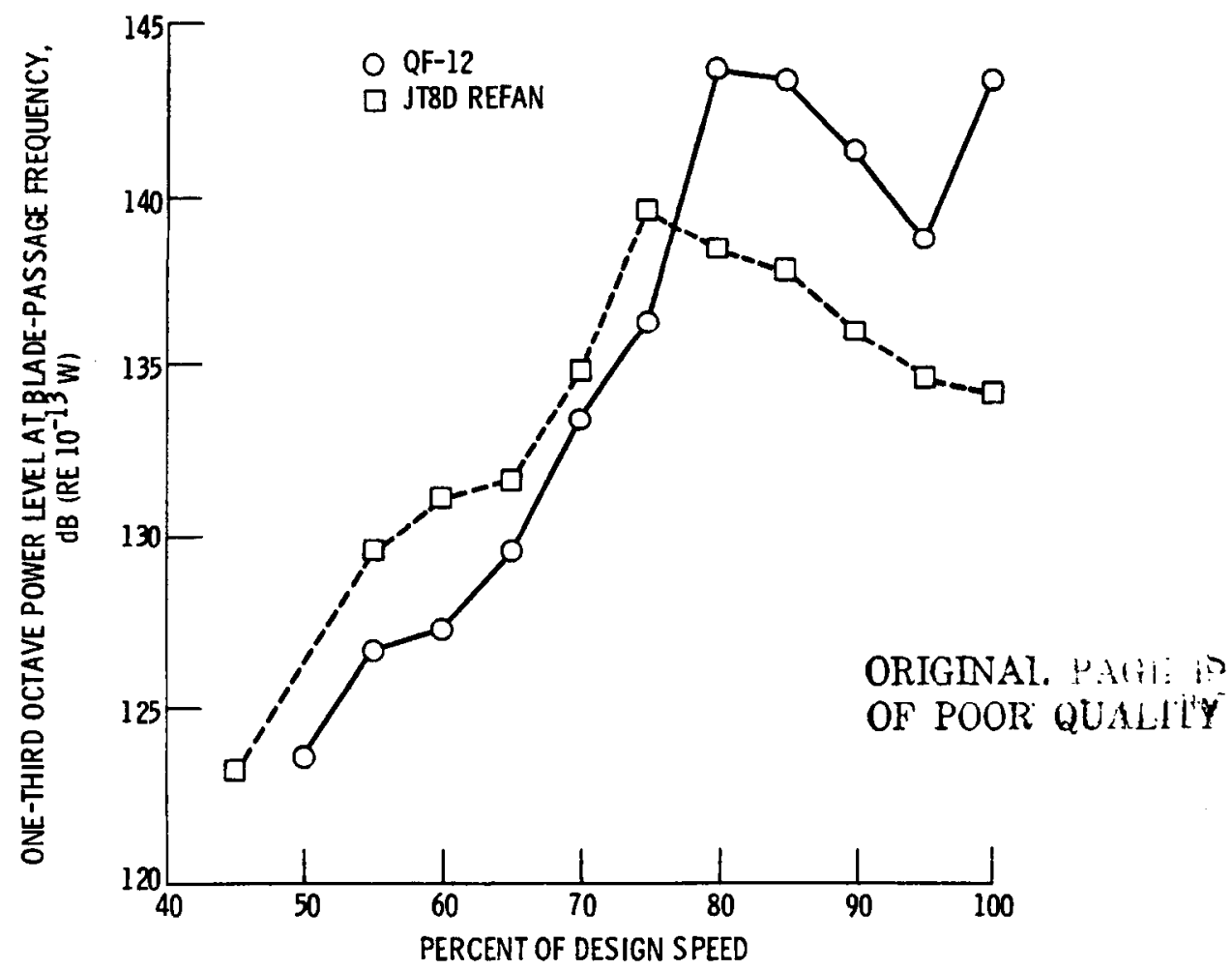

Figure 18. - Comparison of QF-12 and JT8D refan standard operating line blade-passage-tone one-third-octave sound power levels. 


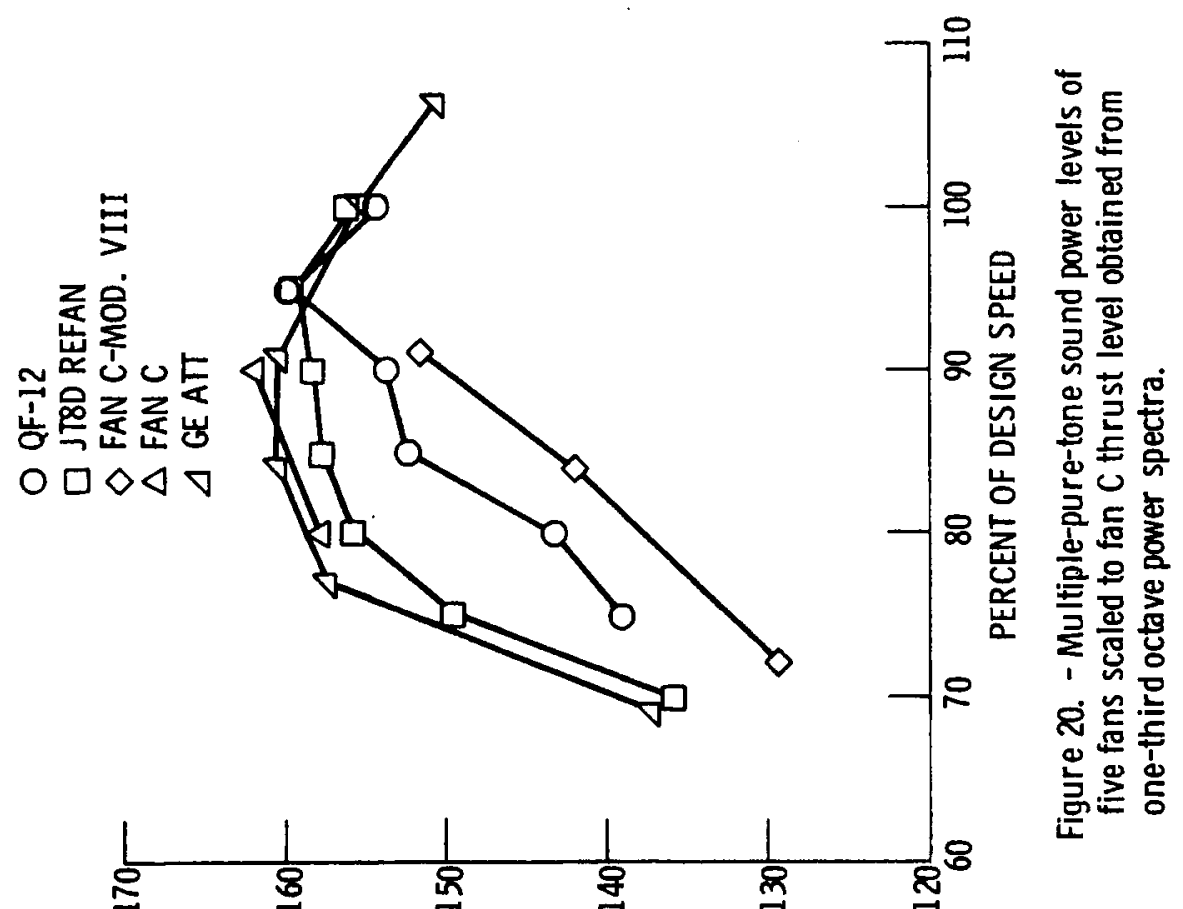

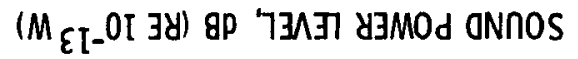

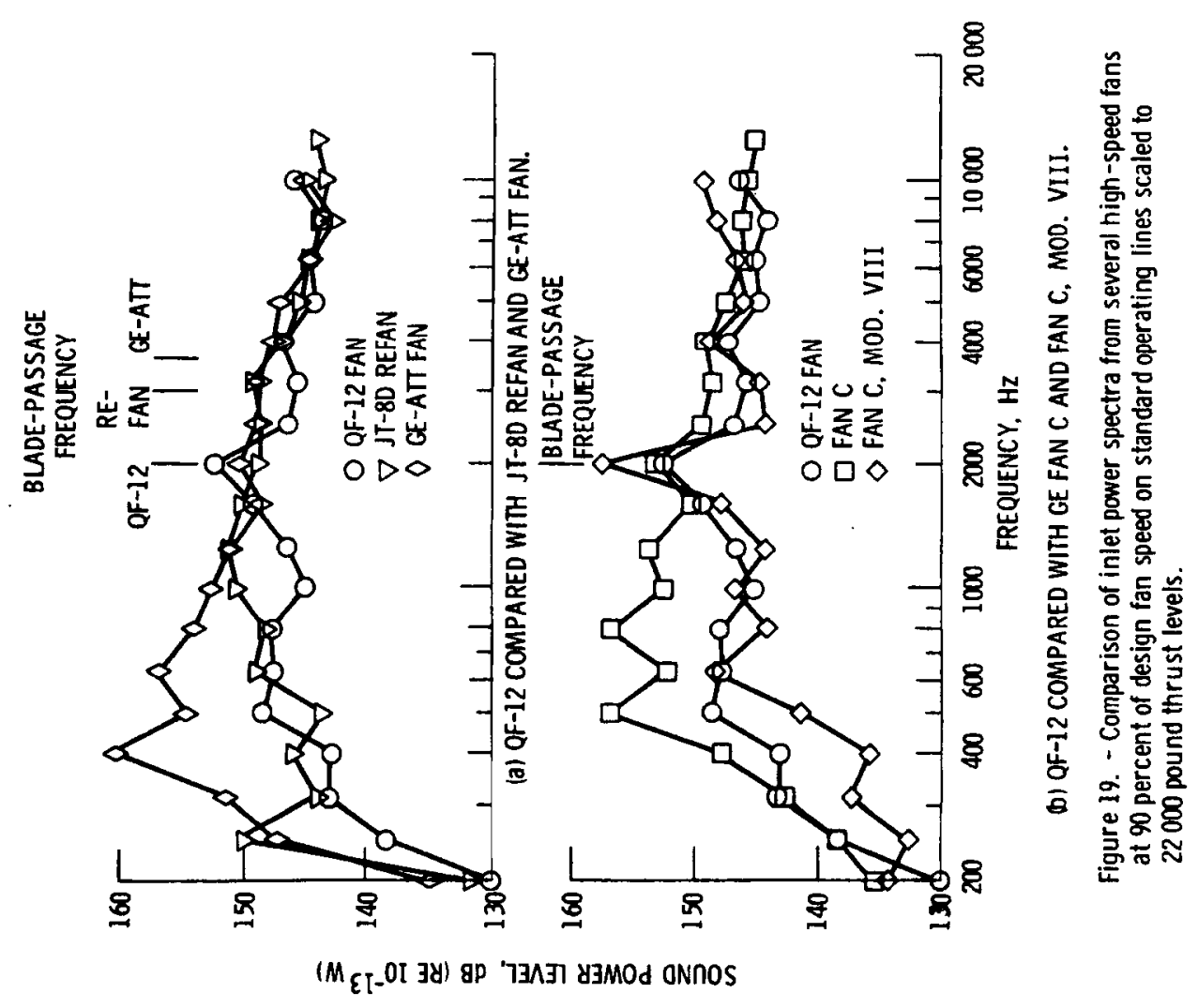




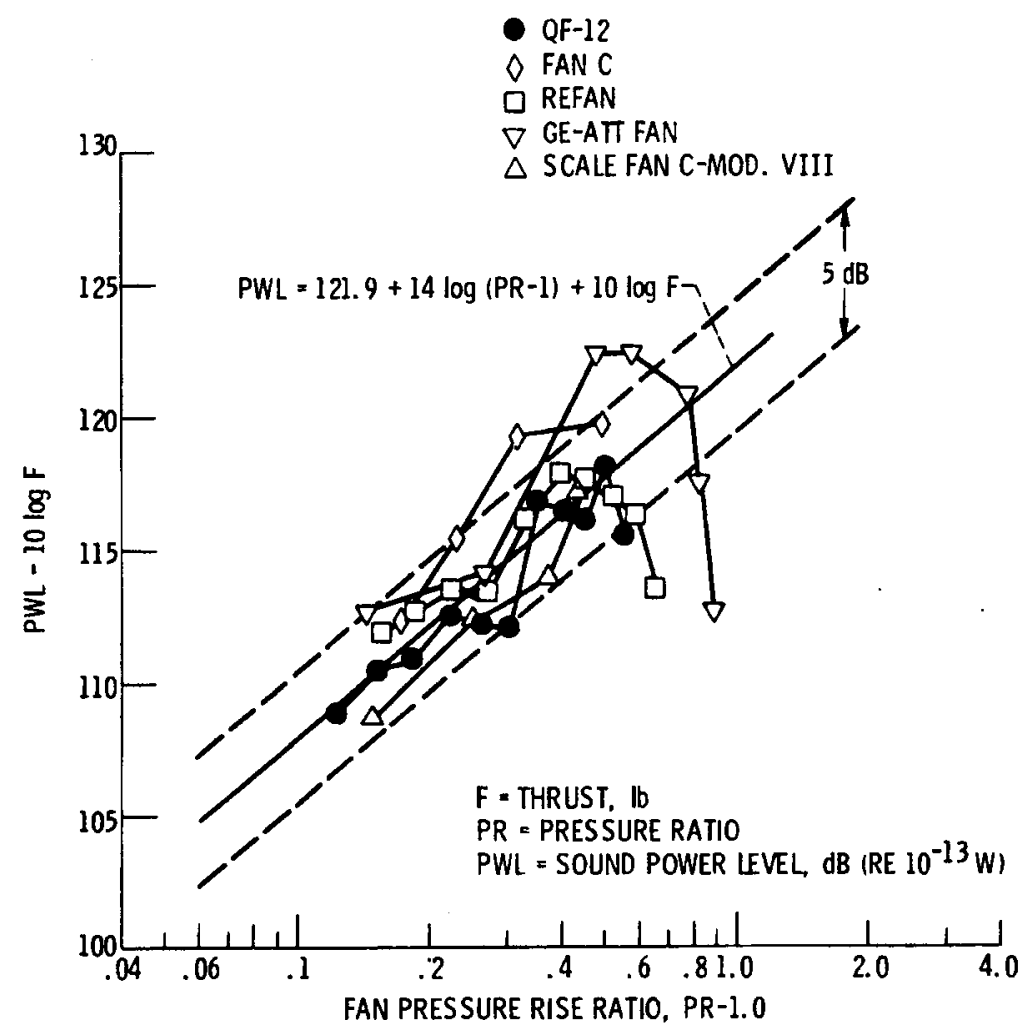

Figure 21. - QF-12 and other high-tip-speed fan inlet sound power levels on a correlation of noise from low-tip-speed fans. 


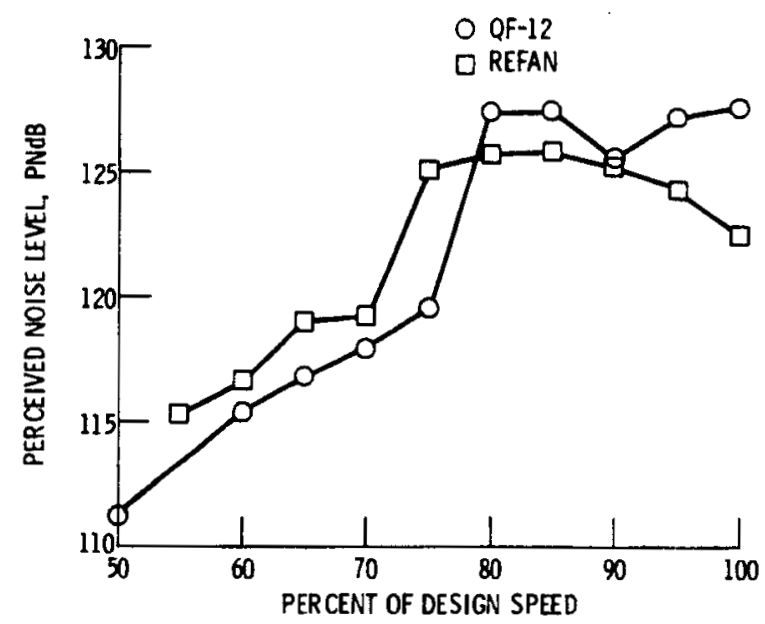

Figure 22. - Comparison of QF-12 and refan maximum perceived noise levels on a $\mathbf{3 0 . 5}$ meter sideline scaled to refan engine thrust level.

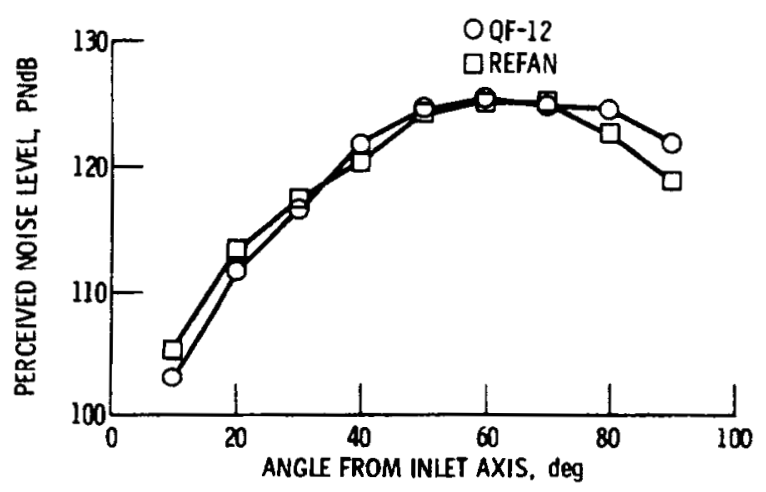

Figure 23. - Comparison of QF-12 and refan perceived noise on a 30.5 meter sideline at 90 percent of design fan speed scaled to refen engine thrust level. 


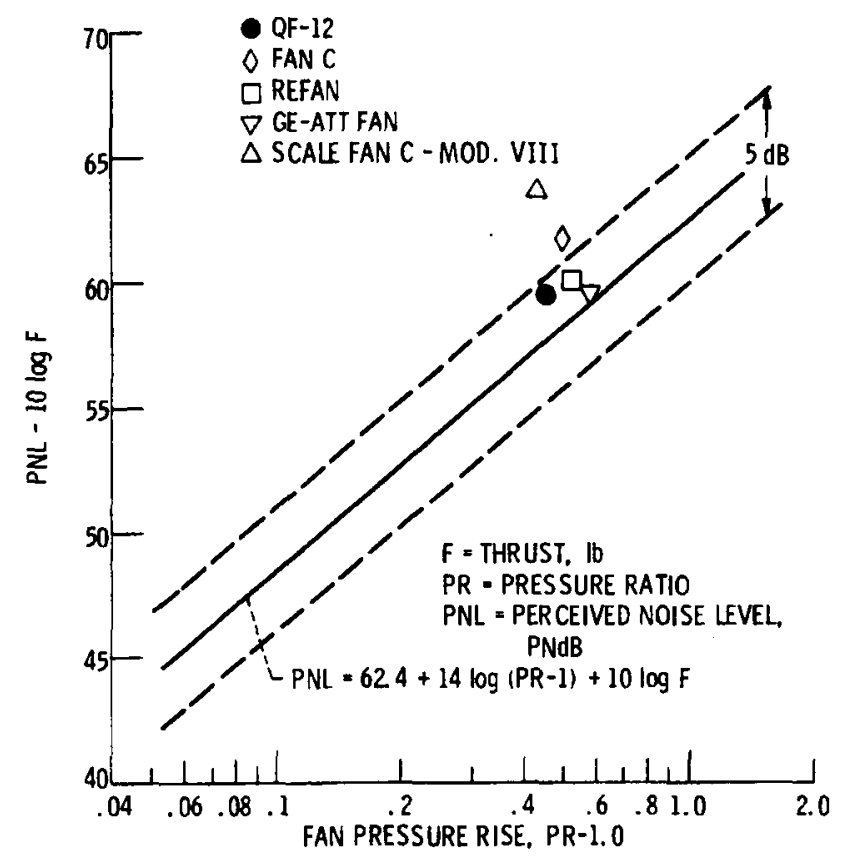

Figure 24. - QF-12 and other high-tip-speed fan takeoff inlet perceived noise on a correlation of noise from low-tip-speed fans, maximu $m$ values on 305 meter sideline. 